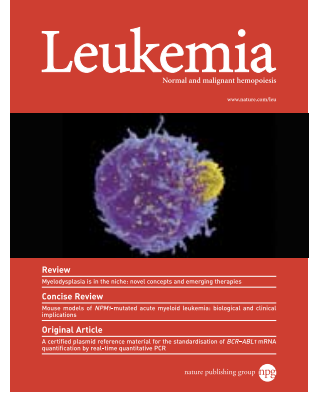

Microenvironmental interactions between endothelial and lymphoma cells - a role for the canonical WNT pathway in Hodgkin lymphoma

F Linke, M Harenberg, M M Nietert, S Zaunig, F von Bonin, A Arlt, M Szczepanowski, H A Weich, S Lutz, C Dullin, P Janovská, M Krafč́iková, L Trantírek, P Ovesná, W Klapper, T Beissbarth, F Alves, V Bryja, L Trümper, J Wilting, D Kube

Cite this article as: $\mathrm{F}$ Linke, $\mathrm{M}$ Harenberg, $\mathrm{M}$ M Nietert, $\mathrm{S}$ Zaunig, $\mathrm{F}$ von Bonin, A Arlt, M Szczepanowski, H A Weich, S Lutz, C Dullin, P Janovská, M Krafč́k ová, L Trantírek, P Ovesná, W Klapper, T Beissbarth, F Alves, V Bryja, L Trümper, J Wilting, D Kube, Microenvironmental interactions between endothelial and lymphoma cells - a role for the canonical WNT pathway in Hodgkin lymphoma, Leukemia accepted article preview 18 August 2016; doi: 10.1038/ leu.2016.232.

This is a PDF file of an unedited peer-reviewed manuscript that has been accepted for publication. NPG are providing this early version of the manuscript as a service to our customers. The manuscript will undergo copyediting, typesetting and a proof review before it is published in its final form. Please note that during the production process errors may be discovered which could affect the content, and all legal disclaimers apply.

Received 25 May 2016; revised 7 July 2016; accepted 3 August 2016; Accepted article preview online 18 August 2016 


\section{Microenvironmental interactions between endothelial and lymphoma cells - a role for the canonical WNT pathway in Hodgkin lymphoma.}

Franziska Linke ${ }^{1}$, Moritz $\underline{\text { Harenberg }}^{1}$, Manuel M. Nietert $^{2}$, Sebastian $\underline{\text { Zaunig }}^{1}$, Frederike $\underline{\text { von Bonin }}{ }^{1}$, Annekatrin Arlt $^{1}$, Monika Szczepanowski ${ }^{3}$, Herbert A. Weich $^{4}$, Susanne

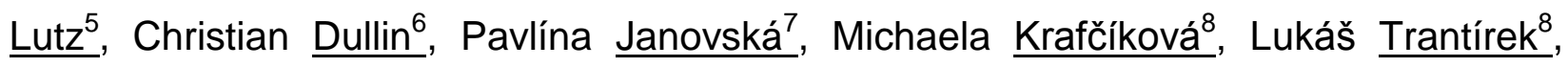
Petra Ovesná $^{9}$, Wolfram $\underline{\text { Klapper }}^{3}$, Tim Beissbarth $^{2}$, Frauke $\underline{\text { Alves }}{ }^{1,6,10}$, Vitezslav Bryja $^{7,11}$, Lorenz Trümper $^{1}$, Jörg Wilting ${ }^{12}$, Dieter $\underline{\text { Kube }}^{1^{*}}$

${ }^{1}$ Clinic of Hematology and Medical Oncology

${ }^{2}$ Department of Medical Statistics

${ }^{5}$ Institute of Pharmacology

${ }^{6}$ Institute of Diagnostic and Interventional Radiology

${ }^{12}$ Department of Anatomy and Cell Biology

1,2,5,6,12 University Medical Centre of the Georg-August University of Göttingen, Göttingen, Germany

${ }^{3}$ Section Hematopathology, UKSH Campus Kiel, Kiel, Germany

4 Department of Chemical Biology, Helmholtz-Centre for Infection Research HZI, Braunschweig, Germany

${ }^{7}$ Faculty of Science, Institute of Experimental Biology

${ }^{8}$ Central European Institute of Technology

${ }^{9}$ Institute of Biostatistics and Analyses

7,8,9 Masaryk University, Brno, Czech Republic

10 Department of Molecular Biology of Neuronal Signals, Max Planck Institute for Experimental Medicine, Göttingen, Germany

${ }^{11}$ Department of Cytokinetics, Institute of Biophysics, Academy of Sciences of Czech Republic, Brno, Czech Republic 
${ }^{*}$ Corresponding author: Dieter Kube; University Medical Centre of the Georg-August University of Göttingen, Clinic of Hematology and Medical Oncology, Robert-Koch-Str. 40, 37075 Göttingen, Germany, +49 551 395307, dieter.kube@med.uni-goettingen.de

Running Title: Canonical WNT signaling in Hodgkin Lymphoma

Financial support:

This work was supported by grants of the Deutsche Forschungsgemeinschaft $\mathrm{Ku}$ 954/12-1 within the Forschergruppe FOR942.

CEITEC-the Central European Institute of Technology is supported by CEITEC 2020 (LQ1601) project with financial contribution made by the Ministry of Education, Youths and Sports of the Czech Republic within special support paid from the National Programme for Sustainability II funds.

V.B and P.J are supported by the grant from the AZV CR, Ministry of Health, Czech Republic, NR 15-29793A.

M.M.N is supported by the BMBF e:Bio Project MetastaSys (Ref: 0316173) and T.B./D.K. by BMBF e:Med Project MMML-Demonstrators (Ref: 031A428B).

S.L. is supported by the German Research Foundation grant SFB1002 TPC02 to SL.

Conflict of interests: The authors have declared that no conflict of interest exists.

Keywords: Microenvironment/ WNT/Endothelial Cells/Hodgkin-Lymphoma/Migration

Word count (excl. references): 4000

Total number of figures: 7 


\section{Abstract}

The interaction between vascular endothelial cells (ECs) and cancer cells is of vital importance to understand tumor dissemination. A paradigmatic cancer to study cell-cell interactions is classical Hodgkin Lymphoma ( $\mathrm{cHL})$ due to its complex microenvironment. The role of the interplay between $\mathrm{CHL}$ and ECs remains poorly understood. Here, we identify canonical WNT pathway activity as important for the mutual interactions between cHL cells and EC.

We demonstrate that local canonical WNT signaling activates $\mathrm{cHL}$ cell chemotaxis towards ECs, adhesion to EC layers and cell invasion using the Wnt-inhibitor Dickkopf, tankyrases and casein kinase I inhibitors but also knock-down of the lymphocyte enhancer binding-factor 1 (LEF-1) and $\beta$-catenin in cHL cells. Furthermore, LEF-1 and $\beta$-catenin-regulated $\mathrm{CHL}$ secretome promoted $\mathrm{EC}$ migration, sprouting and vascular tube formation involving VEGF-A. Importantly, high VEGFA expression is associated with a worse overall survival of $\mathrm{cHL}$ patients.

These findings strongly support the concept that WNTs might function as regulator of lymphoma dissemination by affecting $\mathrm{cHL}$ cell chemotaxis and promoting endothelial cell behavior and thus angiogenesis through paracrine interactions. 


\section{Introduction}

The tumor microenvironment can initiate and promote cancer progression through its influences on tumor cell growth, metastasis and angiogenesis ${ }^{1}$. A paradigmatic cancer entity with a dominant microenvironment and highly complex tumor-stroma interactions is the classical Hodgkin Lymphoma $(\mathrm{cHL})^{2}$. The malignant Hodgkin-Reed-Sternberg (HRS) cells account for less than $1 \%$ of the disease-related cells and highly depend on signaling cross-talk with their neighboring cells. Like no other tumor, $\mathrm{CHL}$ is dependent on paracrine interactions, and thus perfectly serves as a model to study tumor-stroma interactions ${ }^{3}$.

A fundamental characteristic of cancer progression is the tumor cell's ability to migrate and invade into surrounding tissues. Lymphoma cells are derived from usually highly motile but strictly regulated immune cells and their dissemination capacity resembles physiological B- or T-cell migration capabilities e.g. during homing processes ${ }^{4}$. However, for germinal center (GC)-derived lymphoma like cHLs it is necessary to move out of the GC and through corresponding local endothelial cells (ECs) previous to dissemination to other lymph nodes or tissues. Thereby, another critical step for lymphocyte dissemination is the exit from the lymph- but also bloodstream: This includes, for example, movements via high endothelial venules (HEV), which present high levels of the chemokine with C-C motif, ligand 19 (CCL19) and CCL21 at their luminal faces ${ }^{5}$. Till et al. have shown that chronic lymphoid lymphoma (CLL) cells, too, migrate across HEVs into lymph nodes in response to CCL19 and CCL2 ${ }^{6}$. Although a function of chemokine (C-C Motif) receptor 7 (CCR7) has been shown for HRS cell 
homing, the underlying cellular mechanisms have not been studied ${ }^{7}$. The question if HRS cells, in turn, are able to induce tumor characteristics in ECs such as neoangiogenesis has not yet been sufficiently studied. Such a mutual interaction may promote lymphoma dissemination. First insights from the $\mathrm{T}$-cell-derived $\mathrm{cHL}$ cell line L540 showed that $\mathrm{CHL}$ might be capable to induce angiogenesis ${ }^{8}$. We hypothesize that chemokines or other chemoattractants might be exposed by endothelial cells and thus guide HRS cells to metastatic niches. Furthermore, it is assumed, that primary HRS cells are capable of creating gradients of motility altering factors that attract and shape adjacent stromal and endothelial cells.

Comparative analyses revealed differential migration preferences of $\mathrm{cHL}$ cells towards specific chemokines but lacked a detailed analysis of the underlying migratory mechanisms ${ }^{7}$. Moreover, studies on micro-environmental interactions focused on Tcells, macrophages, natural killer (NK) cells, mast cells, eosinophils, dendritic cells, and fibroblasts ${ }^{9-11}$. Notably, studies highlighting $\mathrm{cHL}$ cell - EC interactions are missing, whereas for acute myeloic leukemia (AML), prostate and breast cancer, evidence has been provided that the tumor cell - EC crosstalk influences carcinogenesis and tumor outcome ${ }^{12,13}$. The mutual interactions between $\mathrm{cHL}$ cells and endothelial cells are of fundamental interest but still remain to be studied.

The understanding of the capacity of HRS cells to promote endothelial cell behavior is also necessary to get insight into processes of lymphoma neoangiogenesis. During tumor angiogenesis, local endothelial cells are switched from a resting to an active phenotype by an increase of pro-angiogenic regulators such as vascular endothelial 
growth factors (VEGFs), fibroblast growth factors (FGFs), angiopoietins (ANG) or platelet-derived growth factor (PDGF). Initial angiogenesis then involves the formation of tip cells at the leading front of new vascular sprouts. Next, a lumen is formed and stabilization and maturation processes start ${ }^{14}$. Since tumor cells create an imbalance of multiple angiogenesis regulators, tumor vessels are characterized by high leakiness, poor coverage with vascular supportive cells, reduced functionality (perfusion), and high remodeling potential ${ }^{15}$.

WNT signaling is one pathway, which is involved in different aspects of the above mentioned processes as metastasis but also regulation of angiogenesis. In different tumor entities key components of canonical WNT signaling like lymphocyte enhancerbinding factor-1 (LEF-1) are aberrantly expressed or in case of $\beta$-catenin the activity is deregulated ${ }^{16-20}$. Importantly, during physiological angiogenesis, WNT signaling has also been shown to be an important angiogenic regulator in the developing retina, placenta and ovaries ${ }^{21-23}$. In premalignant colonic epithelial neoplasias, canonical $\beta-$ catenin-dependent WNT signaling has been shown to up-regulate VEGF-A concomitant with angiogenesis 24 . Interestingly, canonical WNT signaling has not only been associated with angiogenesis, but also with migration and metastasis in colorectal cancer, melanoma and lung adenocarcinoma ${ }^{25-27}$. Consequently targeting canonical WNT signaling for example by inhibition of the $\beta$-catenin destruction complex with either casein kinase 1 (CK1) or tankyrases inhibitors might also be of therapeutic interest.

Our study provides evidence that locally active canonical WNT signaling is a regulator of chemokine-guided chemotaxis of $\mathrm{cHL}$ cells towards $\mathrm{CCL} 19$, involving the $\beta$-catenin and 
LEF-1 pathway. Supernatants of LEF-1 and $\beta$-catenin knock-down (KD) cells impaired EC migration, sprouting and tube formation due to reduced secretion of VEGF-A by $\mathrm{CHL}$ cells. Since LEF-1 expression can be observed in 33\% of mixed-cellularity-type HL, and high VEGFA expression is associated with worse overall survival of $\mathrm{cHL}$ patients, our findings indicate that canonical WNT signaling plays a critical role for the outcome in a subset of $\mathrm{cHL}$. 


\section{Materials and Methods}

\section{Cell lines and Reagents}

L428, L1236 and KM-H2 cell lines were obtained from Prof. Volker Diehl (Cologne, Germany) and have been characterized previously ${ }^{40,41}$. In constant intervals, we use a highly specific Ig PCR to test for contaminations. In addition, L428 and L1236 cells have been tested very recently by STR profiling by the DSMZ (Braunschweig, Germany). HUVEC cells have been obtained by Lonza (Basel, Switzerland).

Proteins and small molecule inhibitors included DKK1, DKK2 (both R\&D, Minneapolis, USA), XAV-939 and PF670462 (both Millipore, Billerica, USA).

Primary antibodies were used against LEF-1 (2286), HDAC (2062) (both Cell Signaling Technology, Danvers, USA), $\beta$-catenin (610153) (BD Bioscience, Franklin Lakes, USA), HSP90 (sc-13119) (Santa Cruz, Dallas, USA), GAPDH (ab8245) (abcam, Cambridge, UK) and Tubulin (05-829, Millipore, Billerica, USA).

Secondary antibodies were goat IgG HRP-linked $F(a b$ ')2 fragment against mouse (sc 2005) or rabbit (sc-2004) (Santa Cruz, Dallas, USA).

Phycoerythrin-cyanine 7 (PE-Cy7) conjugated mouse anti-human CCR7 (353226) and the corresponding isotype control (400232) (Biolegend, San Diego, USA) were used for flow cytometry. 


\section{RNA-interference gene knockdown}

Small-interfering RNA (siRNA) against the indicated target genes or nonsense controls (scr, AM4611, Life Technologies, Carlsbad, USA) were transfected into the cells using Nucleofector 2b Device (Lonza, Basel, Switzerland) (Supplementary Methods).

\section{Migration and Invasion Assays}

For migration assays the Boyden chamber with $8 \mu \mathrm{m}$ porous membranes (Neuroprobe Inc., Gaithersburg, USA) and for chemotaxis assays $\mu$-Slide chemotaxis ${ }^{3 D}$ chamber (Ibidi, Martinsried, Germany) with corresponding time-lapse microscopy (Olympus IX81 with Olympus XM-10 camera; Olympus, Shinjuka, Japan) have been used (Supplementary Methods).

\section{Angiogenesis Assays}

Angiogenesis assays including HUVEC Scratch assay, sprouting assay and tube formation assay can be found in the Supplementary Methods part.

\section{Adhesion Assay}

Adhesion assays were performed as described by Zepeda-Moreno et al (Supplementary Methods) ${ }^{50}$.

\section{Chick Chorio-Allantoic Membrane (CAM) Assay}

CAM assays were performed as previously described (Supplementary Methods) ${ }^{51}$. 
Additional methods can be found in the Supplementary Methods part. 


\section{Results}

\section{Locally active canonical WNT signaling mediates CCL19-directed cHL cell chemotaxis}

Using the ex ovo chick chorio-allantoic membrane (CAM) assay the mutual interaction of lymphoma cells and their microenvironment can be studied. Spreading events of GFPexpressing $\mathrm{KM}-\mathrm{H} 2$ cells are observed within 72 hours (Figure 1A). Therefore, after invading through the chorionic epithelium and establishing a primary localized tumor, lymphoma cells start to migrate not only through the stroma but along existing vessels. This is indicative of direct interactions of lymphoma and endothelial cells (ECs). Whether ECs guide this directed migration of the $\mathrm{CHL}$ cells or lymphoma cells reprogram vessel functions and what the underlying mechanisms are has not been clarified yet. The observed lymphoma growth includes processes such as invasiveness, migration and interactions with ECs, and of note, WNT signaling has previously been associated with these mechanisms in other malignancies ${ }^{25-27}$. We therefore studied the canonical WNT pathway and its influence on $\mathrm{CHL}$ cell chemotaxis, as well as interactions with ECs. Very recently we have provided evidence that, among other WNTs, WNT5A is specifically involved in these interactions ${ }^{28}$. Accordingly, different interventions of the canonical WNT signaling were studied in $\mathrm{CHL}$ cells in vitro first.

The migration of $\mathrm{CHL}$ cells towards CCL19 was analyzed using the modified Boyden chamber as described by Höpken et al. ${ }^{7}$. First, the impact of Dickkopf-1 (DKK1) and DKK2, that inhibit the binding of WNTs to the co-receptors LRP5/6, was investigated. 
Each, DKK1 and DKK2, reduced CCL19-mediated $\mathrm{cHL}$ cell chemotaxis by $20 \%$, and by $32 \%$ when used in combination (Figure 1B, Supplementary Figure S1A). This strongly supports the view of a role of WNT signaling in $\mathrm{cHL}$ migration. Next, inhibition of either casein kinase $1(\mathrm{CK} 1)$ or tankyrases as part of the $\beta$-catenin destruction complex was investigated. The inhibition of CK1 (PF670462) or tankyrases (XAV939) was associated with a reduction of cell chemotaxis rates by $45 \%$ and $24 \%$, correspondingly (Figure 1C, Supplementary Figure S1B). Of note, all interventions targeting canonical WNT signaling did neither affect $\mathrm{cHL}$ cell viability nor CCR7 expression (Supplementary Figure S2, S3). To define whether $\beta$-catenin signaling is induced in $\mathrm{CHL}$ cells in an autocrine manner cytosolic and nuclear fractions have been prepared from cHL cells. Immunoblot analysis revealed a substantial proportion of $\beta$-catenin within the nucleus although at low levels (Figure 1D, Supplementary Figure S4). This emphasizes that a basal canonical WNT pathway activity, that is important for cell motility, exists in $\mathrm{cHL}$ cells. Furthermore, enhanced nuclear $\beta$-catenin translocation could be observed after stimulation with conditioned medium of $\mathrm{L} 428$ and $\mathrm{KM}-\mathrm{H} 2$ cells correspondingly arguing that $\mathrm{CHL}$ cells secrete at least one canonical WNT which is able to sustain a basal canonical WNT signaling activity in cHL cells.

\section{Lymphocyte enhancer-binding factor 1 (LEF-1) and $\beta$-catenin are required for $\mathrm{cHL}$ cell chemotaxis}

To further study the role of canonical WNT signaling during $\mathrm{cHL}$ cell chemotaxis, knockdown (KD) of $\beta$-catenin and LEF-1 were performed. The KD of both, LEF-1 and $\beta$ - 
catenin, reduced $\mathrm{cHL}$ chemotaxis rates by approximately $30 \%$ without affecting cell doubling rates or CCR7 expression (Figure 2A,B, Supplementary Figure S5, S6).

This is comparable with the decrease of $\mathrm{cHL}$ cell migration after intervention with DKK1/2 further supporting the hypothesis that canonical WNT-pathway activity is important for $\mathrm{cHL}$ chemotaxis. The KD of LEF-1 and $\beta$-catenin further specifies the inhibition of $\mathrm{cHL}$ migration observed by inhibition of tankyrases and CK-1. In addition, invasion through type-1 collagen was also significantly impaired by LEF- 1 and $\beta$-catenin KD (Figure 2C).

\section{Nuclear LEF-1 is found in HRS cells in a subset of $\mathrm{cHL}$ patients}

Subsequently, the expression of LEF-1 was tested in patients. Importantly, publically available gene expression profiles show that expression of $L E F-1$ in $\mathrm{cHL}$ is almost as high as in chronic lymphatic leukemia (CLL) or Burkitt lymphoma (BL) ${ }^{29,30}$ (Figure 2D). In addition, LEF-1 expression is increased in comparison to normal B-cells including memory and germinal center B-cells (Figure 2E). This argues for aberrant LEF-1 expression in $\mathrm{CHL}$ as it was observed in CLL or $\mathrm{BL}{ }^{17,31,32}$. Since infiltrating $\mathrm{T}$-cells may falsify $L E F-1$ gene expression data in $\mathrm{cHL}$, we performed immunohistochemical analyses of LEF-1. A total of $27 \mathrm{cHL}$ samples were stained, 18 of the nodular-sclerosistype and 9 of the mixed-cellularity-type. Nuclear LEF-1-positive HRS cells were found in $3 / 9(33 \%)$ mixed-cellularity-type and 1/18 (6\%) nodular-sclerosis-type. In Figure 2F a mixed-cellularity $\mathrm{cHL}$ with positive HRS cells and a corresponding case with LEF-1negative HRS cells but positive bystander cells, most likely T-cells, are shown. Taken 
together, the in vitro investigations and the expression analyses of patient samples support the view that canonical WNT signaling is important for cell migration and invasion for a subgroup of $\mathrm{cHL}$.

\section{LEF-1 and $\beta$-catenin influence directionality and velocity of cHL cell migration}

The above used in vitro assays for migration and invasion measure only endpoints of complex and very dynamic motility processes. For further characterization time-lapse studies of KM-H2 cells were performed (Supplementary Videos 1-3). For that purpose $\mathrm{KM}-\mathrm{H} 2$ cells were analyzed in a three-dimensional collagen matrix. $\mathrm{KM}-\mathrm{H} 2$ control (scr si) cells migrated in an amoeboid and highly directed manner along a CCL19 gradient (Figure 3A). In contrast, the majority of LEF-1 and $\beta$-catenin KD cells had difficulties to orientate along the CCL19 gradient and to form protrusions. Therefore, LEF-1 and $\beta$ catenin are obviously important factors that regulate the directionality of $\mathrm{cHL}$ cell migration in a 3D collagen matrix. A further quantitative analysis of whole group movements revealed that cell velocities were significantly reduced from 1.1 to 0.6 and $0.4 \mu \mathrm{m} / \mathrm{min}$ after LEF-1 and $\beta$-catenin KD, respectively (Figure 3B). Similarly, covered distances including both the euclidean and accumulated distances decreased strongly to approximately $30 \%$ and $50 \%$, respectively, as compared to control KM-H2 cells (Figure 3C,D). Next, each cell track was converted into a biostatistical fingerprint as described previously to compare the track characteristics between LEF-1 and $\beta$-catenin KD cells 28. Data are summarized as a similarity heat map (Supplementary Figure S7). Tracks of the control (scr si) cells clearly separated from tracks of corresponding KD cells. By hierarchical clustering the 15 most different movement classes were calculated and 
analyzed (Figure 3E). One group of movement classes (1-7) was characterized by multiple short and few intermediate-sized intermediate steps. These paths were found in all cell groups. Other classes were characterized by very short steps or even halts (classes 8-11). These classes predominantly represented the behavior of LEF-1 and $\beta$ catenin KD cells. The third group of cell migration paths is characterized by mostly straight and long single steps (classes 12-15). These classes are strikingly overrepresented in the control group. Of note, classes 8-11 displayed not continuous, but always interrupted tracks. Since these classes predominantly grouped with the LEF1 and $\beta$-catenin $\mathrm{KD}$ cells, they are obviously characteristic for cells with defective canonical WNT signaling. This further supports our hypothesis that canonical WNT signaling is required for directed cell migration not only in 2- but also 3D cell culture conditions.

\section{Canonical WNT signaling regulates the impact of $\mathrm{cHL}$ cells on endothelial cell migration, sprouting and tube formation}

Dissemination of HRS cells includes migration out of the GC but then HRS cells with metastatic potential exit the tumor lymph node via efferent lymph vessel or through HEVs and migrate predictably to the next functional node. As in L540 T-cell-derived L540 $\mathrm{cHL}$ cells may stimulate angiogenesis, it is of clinical interest to test the influence of HRS cell secretome on endothelial cell (EC) function and behavior in relation to canonical WNT signaling, to receive further insight into the regulatory molecular networks ${ }^{8}$. In modified Boyden chamber assays, supernatants of LEF-1 knockdown $\mathrm{cHL}$ cells were less potent in attracting HUVECs than corresponding control cells (Figure 4A, 
Supplementary Figure S8A). Migration of ECs towards the supernatant of LEF-1 KD $\mathrm{CHL}$ cells was reduced to $50 \%$ compared to control $\mathrm{cHL}$ supernatant. This suggests that LEF-1 controls the $\mathrm{cHL}$ secretome and supports pro-migratory EC behavior. This was also supported in scratch assays, where HUVECs were directly incubated with supernatant of LEF-1 KD cHL cells. Comparable to the analysis of HUVECs in Boyden chamber assays, migration rates were impaired (Figure 4B,C; Supplementary Figure S8B,C). Therefore, the influence of the $\mathrm{cHL}$ cell secretome on $\mathrm{EC}$ migration is further underpinned. In conclusion, LEF-1 is not only an important and direct regulator of migration-associated pathways in $\mathrm{cHL}$ cells but also of secreted factors that act as chemoattractant for ECs.

To model initial sprouting of capillaries a spheroid assay was applied. HUVEC spheroids incubated with conditioned medium of LEF-1-knockdown $\mathrm{cHL}$ cells sprouted only half as efficient as the controls (Figure 5A,B). However, when sprouting events occurred, neither the number of sprouts nor their cumulative length differed between LEF-1 KD and control experiments (Figure 5C,D). This suggests that LEF-1-regulated secreted factors from $\mathrm{cHL}$ cells are of importance for the initialization of EC sprouting rather than the morphological characteristics of the sprouts.

In the next steps of angiogenesis, capillaries elongate and a lumen is formed. This can partially be remodeled in vitro in the so-called tube formation assays. Here, we analyzed the influence of the secretome of $\mathrm{cHL}$ cells on the capacity of HUVECs to form branched, tube-like structures on extracellular matrix. Supernatants of $\mathrm{cHL}$ cells were capable of supporting tube formation of HUVECs (Figure 5E,F), although less efficient 
than the complete growth factor-enriched EC medium. CM derived from LEF-1 and $\beta$ catenin KD cells showed a diminished capacity to support tube formation when compared to respective control CM. Therefore, our data reveal that secreted factors from $\mathrm{cHL}$ cells promote several separate steps of angiogenesis in ECs and this is dependent on the canonical WNT-pathway components LEF-1- and $\beta$-catenin.

Finally, we studied direct interactions, which are relevant for tumor cell dissemination, and performed adhesion assays to investigate the capability of $\mathrm{CHL}$ cells to attach to ECs as well as type-1 collagen. This adhesion to ECs and to type-1 collagen was significantly impaired by the KD of LEF-1 in KM-H2 and L428 cells (Figure 5G, Supplementary Figure S8D). Furthermore, LEF-1 regulated not only the migratory activity of HUVECs, as shown above, but also influenced their metabolic activity. This was significantly reduced after treatment with supernatant of LEF-1 KD cHL cells as revealed by MTT assay (Supplementary Figure S8E-F).

\section{Canonical WNT signaling regulates lymphoma formation and vascularization in CAM assays}

Since angiogenesis is a multi-step process, in vitro assays, which analyze isolated mechanisms, are of limited information. A well-established system to monitor the whole process of tumor angiogenesis, including vessel formation and destruction, is the chorioallantoic membrane (CAM) assay. As shown in Figure 1A, it is also a suitable system for $\mathrm{cHL}$ cells. Lymphomas produced from tankyrases inhibitor-treated $\mathrm{KM}-\mathrm{H} 2$ 
cells were significantly smaller and showed less hemorrhages (Figure 6A-C). Furthermore, in control tumors, bleeding was very prominent. Numerous micro-vessels branching from conducting vessels were present in the lymphoma and were obviously leaky (black arrows in Figure 6D left). In contrast, vessel integrity was mostly preserved in tumors from XAV939 pre-treated $\mathrm{cHL}$ cells (yellow arrows in Figure 6D right). In addition, we applied micro-CT techniques to virtually dissect the tumors and monitor vascular networks in the whole specimens. DMSO-treated control tumors contained numerous branched vessels and vessel residuals (arrows in Figure 6E, left). Vascular sprouts from pre-existing CAM vessel penetrating into the lymphomas could be observed and support the view of cHL-mediated neoangiogenesis in this assay (Figure 6E left). One explanation might be that the $\mathrm{CHL}$ secretome affects ECs and new lymphoma-associated vessel formation taking into account the above described in vitro analysis. Importantly, the lymphomas derived from tankyrases inhibitor-pre-treated cHL cells were hardly capable of forming such complex vascular networks in the tumor mass thus underscoring the impact of canonical WNT signaling in $\mathrm{cHL}$ cells on ECs and vessel formation (Figure 6E right).

VEGF-A levels in cHL cell supernatant depend on LEF-1 and $\beta$-catenin, and VEGFA expression is predictive for $\mathrm{cHL}$ outcome

Since canonical WNT signaling in $\mathrm{cHL}$ had such a strong impact on endothelial cell behavior, we were interested in the underlying mechanisms. We speculated that the differential tumor biology may either be due to metabolic differences of the differently treated $\mathrm{cHL}$ cells themselves, or to differences in the secretion of pro-angiogenic factors. 
To test the first hypothesis, NMR analyses of LEF-1 KD cells were performed (Supplementary Figure S9). However, these data revealed no major differences in content of metabolites, suggesting that the metabolic rates did not change significantly during the LEF-1 KD. The second hypothesis would suggest that LEF-1-knockdown cells secrete less pro-angiogenic factors than the control cells. One potent factor, which induces in vivo migration, sprouting and lumen formation of endothelial cells, is VEGF-A ${ }^{33}$. ELISAs of L428 and KM-H2 control supernatants reveal VEGF-A levels of 270 and $320 \mathrm{pg} / \mathrm{ml}$ per $10^{5}$ cells, respectively (Figure 7A). This amount of VEGF-A secreted by $\mathrm{cHL}$ cells was reduced not only by LEF-1 but also $\beta$-catenin KD. The secreted VEGF-A levels dropped by approximately $25-30 \%$. Thus, LEF-1 as well as $\beta$ catenin are affecting the secretion of VEGF-A in CHL cells.

Additional analyses of publically available patient microarray data revealed a significant correlation between VEGFA expression and the overall survival of $\mathrm{cHL}$ patients (Figure 7B) ${ }^{34}$. While approximately $90 \%$ of patients with low VEGFA expression survived 10 years or longer, only $65 \%$ with high expression levels were alive after 10 years $(P=$ 0.008). This indicates that aberrant LEF-1 expression and nuclear localization are observed in $\mathrm{cHL}$ cells. Importantly, VEGFA expression is directly correlated with patient's survival and therapy response. We therefore hypothesize that the regulation of VEGF-A secretion by LEF-1/ß-catenin WNT signaling in vitro might also take place in vivo and contribute to VEGFA expression in patients. 


\section{Discussion}

The tumor microenvironment greatly influences tumorigenesis, which is very important in $\mathrm{CHL}^{2}$. The infiltration with immune cells provides essential survival signals for HRS cells and was central for recent investigations so far ${ }^{3,35}$. However, mechanisms for dissemination of $\mathrm{cHL}$ cells, for example along the vascular system or the interactions with the lymphoma endothelium, have rarely been studied. Here, we describe mutual interactions between $\mathrm{cHL}$ cells and vascular endothelial cells and provide compelling evidence that LEF-1 and $\beta$-catenin are of importance in these processes.

Our study highlights the role of canonical WNT-pathway regulating directed movement of analyzed lymphoma cells and thus towards vascular niches mediated by chemokines likely presented by ECs. But also the attraction of ECs by $\mathrm{cHL}$ cells is regulated by WNT signaling. Therefore, we show mechanistically that canonical WNT signaling is a regulator of the mutual endothelium-lymphoma interplay. Our data support the view that $\mathrm{cHL}$ cells are able to migrate towards ECs in response to chemokines in a LEF-1 and $\beta$ catenin-dependent manner and also attract ECs most likely via VEGF-A secretion. Importantly, for both processes canonical WNT signaling of lymphoma cells is a prerequisite.

Blocking canonical WNT signaling of $\mathrm{cHL}$ cells at different levels of the pathway resulted in reduced chemotactic migration and invasion. Interestingly, the LEF-1 or $\beta$-catenin influence was even more obvious in 3D migration assays with type-1 collagen. From these studies the hypothesis can be deduced for future studies that there is a specific 
role for collagen-mediated canonical WNT signaling in $\mathrm{cHL}$ cell movements. This hypothesis has to take into account the recent observation about the DDR1 and DDR2 signaling pathway ${ }^{36,37}$. However, future studies will have to investigate whether the interaction of $\mathrm{cHL}$ cells with collagen is regulating WNT mediated lymphoma cell motility or whether the canonical WNT pathway is a prerequisite for collagen-mediated chemotaxis.

The migration and adhesion of lymphoma cells to HUVECs is a model to study the dissemination process of the tumor cells and may have a major impact on the understanding of the outcome of the disease. Although not investigated for $\mathrm{cHL}$, the adherence to HEVs has been associated with the dissemination potential of NonHodgkin lymphomas, which has been confirmed in lymphoma mouse models ${ }^{38,39}$. Therefore, endothelium-mediated chemotaxis and adherence of lymphoma cells to ECs can be regarded as an important parameter for $\mathrm{cHL}$ progression. Given this, the question rises if $\mathrm{cHL}$ cells gain an additional benefit from their proximity to $\mathrm{ECs}$, despite the apparent induction of angiogenesis and facilitation of dissemination. One important observation by Fhu and colleagues was, that $\mathrm{cHL}$ cells actively secrete lymphotoxin- $\alpha$, which caused the upregulation of adhesion molecules in ECs thereby recruiting CD4 ${ }^{+}$ naïve T-cells ${ }^{40}$. This suggests that ECs can actively participate in the recruitment of lymphoma-supporting T-cells, and shape the $\mathrm{cHL}$ microenvironment towards a protumorigenic niche. The secretion of VEGF-A by $\mathrm{cHL}$ cells fits into this scenario of an active cHL-EC interaction. But our data also show that additionally separate functions for ECs in $\mathrm{cHL}$ progression exist. 
In a previous study, $70.6 \%(41 / 61)$ of immunostained $\mathrm{cHL}$ samples were positive for VEGF-A ${ }^{41}$. Our reevaluation of published patient's data shows that high VEGFA gene expression correlates with a significantly worse overall survival ${ }^{34}$. These results are consistent with previous findings on the importance of neovascularization and proangiogenic factors in $\mathrm{cHL}$ cases ${ }^{42-45}$. Nevertheless, VEGF-A might not only be secreted by $\mathrm{cHL}$ cells but also by cells of the lymphoma microenvironment. Tumorassociated macrophages have been shown as involved in different aspects of angiogenesis regulation ${ }^{46}$. In the present study we provide evidence for WNT-regulated signaling mechanisms of VEGF-A secretion in $\mathrm{CHL}$. Recently, a proangiogenic potential of the T-cell-derived $\mathrm{L} 540 \mathrm{cHL}$ cell line has been shown using $1 \%$ serum cell culture conditions $^{8}$. We cannot exclude that in our experiments remnants of serum in the $\mathrm{CM}$ may have led to an overestimation of the proangiogenic potential of $\mathrm{B}$-cell-derived $\mathrm{cHL}$ cells. However, the study of WNT functions requires higher serum concentrations to avoid precipitation of WNT proteins. Nevertheless, by comparing LEF-1 knockdown and control cells we have clearly shown an involvement of LEF-1 in angiogenic processes. This further supports the view about the angiogenic potential of B-cell-derived cHL cells. As proposed by Marinaccio et al. ${ }^{47}$ we were able to evaluate the proangiogenic potential of $\mathrm{CHL}$ cells in CAM assays in vivo, and demonstrated that canonical WNT signaling has an impact on angiogenesis.

Our experimental data provide compelling evidence, that for $\mathrm{cHL}$ cells basal (constitutively) active canonical WNT signaling is required to attract ECs and to enhance their migration, sprouting and tube formation capacities. We identified VEGF-A as a 
factor secreted in a LEF-1- and $\beta$-catenin-dependent manner. Nevertheless, it can be assumed that the secretion of other angiogenesis modulating factors like FGF might be regulated by canonical WNT signaling in $\mathrm{CHL}$ cells. To assess the complete effects of LEF-1 and $\beta$-catenin signaling in $\mathrm{cHL}$, a comprehensive secretome analysis shall be performed in future experiments. In addition the LEF-1 and $\beta$-catenin mediated WNT signaling might be part of a so far unrevealed network affecting VEGF-A secretion and thus influence endothelial cells in general. Other pathways that are well-known for their contribution to $\mathrm{cHL}$ pathogenesis might also be involved and have to be investigated for their impact on endothelial cell behavior in the future.

In summary, our results show that canonical WNT signaling significantly affects $\mathrm{cHL}$ cell chemotaxis and secreted VEGF-A levels, leading to remarkable pro-lymphomagenic effects in vitro and in vivo. Therefore, larger clinical trials with anti-VEGF-A drugs targeting the interplay of $\mathrm{cHL}$ cells and ECs, and probably complemented with WNT inhibitors, will be needed to evaluate the impact of canonical WNT signaling and the cHL-endothelial interaction as therapeutic targets. 


\section{Acknowledgements}

We are very thankful to Mrs. S. Schwoch for her technical assistance in the histological analysis of the CAM tumors and Mrs. G. Lutze for some advice in the vascular sprouting assay. 


\section{Author Contributions}

F.L., M.H., S.Z., F.v.B., did most of the experiments with A.A., C.D., S.L., M.M.N. and J.W. contributing to specific experiments as flow cytometry, Micro-CT analysis of the chick chorio-allantoic assay, time-lapse experiments, cell track analysis and data interpretation as well as chick chorio-allantoic model characterization. M.S. and W.K. performed IHC analysis. P.J. and V.B. analyzed microarray data from Oncomine. M.K. and L.T. performed NMR studies and P.O. performed the corresponding cluster analysis. V.B., J.W., T.B., F.A., and L.T. were involved in manuscript writing and the final approval. F.L. and D.K. designed the research, analyzed and interpreted data, and wrote the finally approved manuscript. 


\section{References}

1. Hanahan D, Weinberg RA. Hallmarks of cancer: the next generation. Cell. 2011;144(5):646-74.

2. Aldinucci D, Gloghini A, Pinto A, De Filippi R, Carbone A. The classical Hodgkin's lymphoma microenvironment and its role in promoting tumour growth and immune escape. J Pathol. 2010 Jul;221(3):248-63.

3. Liu Y, Sattarzadeh A, Diepstra A, Visser L, van den Berg A. The microenvironment in classical Hodgkin lymphoma: an actively shaped and essential tumor component. Semin Cancer Biol. 2014 Feb;24:15-22.

4. Pals ST, de Gorter DJJ, Spaargaren M. Lymphoma dissemination: the other face of lymphocyte homing. Blood. 2007 Nov 1;110(9):3102-11.

5. Baekkevold ES, Yamanaka T, Palframan RT, Carlsen HS, Reinholt FP, von Andrian UH, et al. The CCR7 ligand elc (CCL19) is transcytosed in high endothelial venules and mediates $T$ cell recruitment. $J$ Exp Med. 2001;193(9):1105-12.

6. Till KJ, Lin K, Zuzel M, Cawley JC. The chemokine receptor CCR7 and alpha4 integrin are important for migration of chronic lymphocytic leukemia cells into lymph nodes. Blood. 2002;99(8):2977-84.

7. Höpken UE, Foss H-D, Meyer D, Hinz M, Leder K, Stein H, et al. Up-regulation of the chemokine receptor CCR7 in classical but not in lymphocyte-predominant Hodgkin disease correlates with distinct dissemination of neoplastic cells in lymphoid organs. Blood. 2002 Feb 15;99(4):1109-16.

8. Celegato M, Borghese C, Casagrande N, Mongiat M, Kahle XU, Paulitti A, et al. Preclinical activity of the repurposed drug auranofin in classical Hodgkin lymphoma. Blood. 2015 Sep 10;126(11):1394-7.

9. Pinto A, Aldinucci D, Gloghini A, Zagonel V, Degan M, Improta S, et al. Human eosinophils express functional CD30 ligand and stimulate proliferation of a Hodgkin's disease cell line. Blood. 1996 Nov 1;88(9):3299-305.

10. Molin D, Fischer M, Xiang Z, Larsson U, Harvima I, Venge P, et al. Mast cells express functional CD30 ligand and are the predominant CD30L-positive cells in Hodgkin's disease. Br J Haematol. 2001 Sep;114(3):616-23.

11. Schreck S, Friebel D, Buettner M, Distel L, Grabenbauer G, Young LS, et al. Prognostic impact of tumour-infiltrating Th2 and regulatory $T$ cells in classical Hodgkin lymphoma. Hematol Oncol. 2009 Mar;27(1):31-9.

12. Zhang J, Ye J, Ma D, Liu N, Wu H, Yu S, et al. Cross-talk between leukemic and endothelial cells promotes angiogenesis by VEGF activation of the Notch/DII4 pathway. Carcinogenesis. 2013;34(3):667-77. 
13. Nagaraj SRM, Shilpa P, Rachaiah K, Salimath BP. Crosstalk between VEGF and MTA1 signaling pathways contribute to aggressiveness of breast carcinoma. Mol Carcinog. 2015 May;54(5):333-50.

14. Carmeliet P, Jain RK. Molecular Mechanisms and and clinical applications of angiogenesis. Nature. 2011;473(7347):298-307.

15. Jain RK. Normalization of tumor vasculature: an emerging concept in antiangiogenic therapy. Science. 2005;307(5706):58-62.

16. Gelebart P, Anand M, Armanious H, Peters AC, Bard JD, Amin HM, et al. Constitutive activation of the Wnt canonical pathway in mantle cell lymphoma. Blood. 2008;112(13):5171-9.

17. Gutierrez A, Tschumper RC, Wu X, Shanafelt TD, Eckel-Passow J, Huddleston $\mathrm{PM}$, et al. LEF-1 is a prosurvival factor in chronic lymphocytic leukemia and is expressed in the preleukemic state of monoclonal B-cell lymphocytosis. Blood. 2010 Oct 21;116(16):2975-83.

18. Wang W, Ji P, Steffen B, Metzger R, Schneider PM, Halfter $\mathrm{H}$, et al. Alterations of lymphoid enhancer factor-1 isoform expression in solid tumors and acute leukemias. Acta Biochim Biophys Sin (Shanghai). 2005 Mar;37(3):173-80.

19. Murakami T, Toda S, Fujimoto M, Ohtsuki M, Byers HR, Etoh T, et al. Constitutive activation of Wnt/beta-catenin signaling pathway in migration-active melanoma cells: role of LEF-1 in melanoma with increased metastatic potential. Biochem Biophys Res Commun. 2001 Oct 19;288(1):8-15.

20. Morin PJ, Sparks AB, Korinek V, Barker N, Clevers $H$, Vogelstein B, et al. Activation of beta-catenin-Tcf signaling in colon cancer by mutations in betacatenin or APC. Science. 1997;275(5307):1787-90.

21. Xu Q, Wang Y, Dabdoub A, Smallwood PM, Williams J, Woods C, et al. Vascular development in the retina and inner ear: Control by Norrin and Frizzled-4, a highaffinity ligand-receptor pair. Cell. 2004;116(6):883-95.

22. Hsieh M, Boerboom D, Shimada M, Lo Y, Parlow AF, Luhmann UFO, et al. Mice Null for Frizzled4 (Fzd4-/-) Are Infertile and Exhibit Impaired Corpora Lutea Formation and Function. Biol Reprod. 2005;73(6):1135-46.

23. Luhmann UFO, Meunier D, Shi W, Lüttges A, Pfarrer C, Fundele R, et al. Fetal loss in homozygous mutant Norrie disease mice: A new role of Norrin in reproduction. Genesis. 2005;42:253-62.

24. Zhang X, Gaspard JP, Chung DC. Regulation of Vascular Endothelial Growth Factor by the Wnt and K-ras Pathways in Colonic Neoplasia. Cancer Res. 2001;61:6050-4.

25. Qi J, Yu Y, Akilli Öztürk Ö, Holland JD, Besser D, Fritzmann J, et al. New Wnt/ßcatenin target genes promote experimental metastasis and migration of colorectal 
cancer cells through different signals. Gut. 2015;1-12.

26. Gallagher SJ, Rambow F, Kumasaka M, Champeval D, Bellacosa A, Delmas V, et al. Beta-catenin inhibits melanocyte migration but induces melanoma metastasis. Oncogene. 2013 Apr 25;32(17):2230-8.

27. Nguyen DX, Chiang AC, Zhang XH-FF, Kim JY, Kris MG, Ladanyi M, et al. WNT/TCF signaling through LEF1 and HOXB9 mediates lung adenocarcinoma metastasis. Cell. Elsevier Ltd; 2009 Jul 10;138(1):51-62.

28. Linke F, Zaunig S, Nietert MM, von Bonin F, Lutz S, Dullin C, et al. WNT5A: a motility-promoting factor in Hodgkin lymphoma. Oncogene. 2016 Jun 6;

29. Brune V, Tiacci E, Pfeil I, Döring C, Eckerle S, van Noesel CJM, et al. Origin and pathogenesis of nodular lymphocyte-predominant Hodgkin lymphoma as revealed by global gene expression analysis. J Exp Med. 2008 Sep 29;205(10):2251-68.

30. Basso K, Margolin AA, Stolovitzky G, Klein U, Dalla-Favera R, Califano A. Reverse engineering of regulatory networks in human B cells. Nat Genet. 2005;37(4):382-90.

31. Erdfelder F, Hertweck M, Filipovich A, Uhrmacher S, Kreuzer K-A. High lymphoid enhancer-binding factor-1 expression is associated with disease progression and poor prognosis in chronic lymphocytic leukemia. Hematol Rep. 2010;2(1):e3.

32. Walther N, Ulrich A, Vockerodt M, von Bonin F, Klapper W, Meyer K, et al. Aberrant lymphocyte enhancer-binding factor 1 expression is characteristic for sporadic Burkitt's lymphoma. Am J Pathol. American Society for Investigative Pathology; 2013 Apr;182(4):1092-8.

33. Senger DR, Van de Water L, Brown LF, Nagy JA, Yeo KT, Yeo TK, et al. Vascular permeability factor (VPF, VEGF) in tumor biology. Cancer Metastasis Rev. 1993 Sep;12(3-4):303-24.

34. Steidl C, Lee T, Shah SP, Farinha P, Han G, Nayar T, et al. Tumor-Associated Makrophages and Survival in Classic Hodgkin's Lymphoma. N Engl J Med. 2010 Jan 29;362(10):875-85.

35. Steidl C, Connors JM, Gascoyne RD. Molecular Pathogenesis of Hodgkin's Lymphoma: Increasing Evidence of the Importance of the Microenvironment. J Clin Oncol. 2011;29(14):1812-26.

36. Afonso P V, McCann CP, Kapnick SM, Parent CA. Discoidin domain receptor 2 regulates neutrophil chemotaxis in $3 \mathrm{D}$ collagen matrices. Blood. 2013;121(9):1644-50.

37. Cader FZ, Vockerodt M, Bose S, Nagy E, Brundler M-A, Kearns P, et al. The EBV oncogene LMP1 protects lymphoma cells from cell death through the collagenmediated activation of DDR1. Blood. 2013 Dec;122(26):4237-45.

38. Stauder R, Hamader S, Fasching B, Kemmler G, Thaler J, Huber H. Adhesion to 
high endothelial venules: a model for dissemination mechanisms in non-Hodgkin's lymphoma. Blood. 1993;82(1):262-7.

39. Bargatze RF, Wu NW, Weissman IL, Butcher EC. High Endothelial Venule Binding As A Predictor Of The Dissmenination Of Passaged Murine Lymphomas. J Exp Med. 1987;166:1125-31.

40. Fhu CW, Graham AM, Yap CT, Al-Salam S, Castella A, Chong SM, et al. ReedSternberg cell-derived lymphotoxin- $\alpha$ activates endothelial cells to enhance T-cell recruitment in classical Hodgkin lymphoma. Blood. 2014 Nov 6;124(19):2973-82.

41. Doussis-Anagnostopoulou IA, Talks KL, Turley H, Debnam P, Tan DC, Mariatos G, et al. Vascular endothelial growth factor (VEGF) is expressed by neoplastic Hodgkin-Reed-Sternberg cells in Hodgkin's disease. J Pathol. 2002;197(5):67783.

42. Mizuno H, Nakayama T, Miyata Y, Saito S, Nishiwaki S, Nakao N, et al. Mast cells promote the growth of Hodgkin's lymphoma cell tumor by modifying the tumor microenvironment that can be perturbed by bortezomib. Leukemia. Nature Publishing Group; 2012;26(10):2269-76.

43. Giles FJ, Vose JM, Do K-A, Johnson MM, Manshouri T, Bociek G, et al. Clinical relevance of circulating angiogenic factors in patients with non-Hodgkin's lymphoma or Hodgkin's lymphoma. Leuk Res. 2004 Jun;28(6):595-604.

44. Dimtsas GS, Georgiadi EC, Karakitsos P, Vassilakopoulos TP, Thymara I, Korkolopoulou $P$, et al. Prognostic significance of immunohistochemical expression of the angiogenic molecules vascular endothelial growth factor-A, vascular endothelial growth factor receptor-1 and vascular endothelial growth factor receptor-2 in patients with classical Hodgkin. Leuk Lymphoma. 2014 Mar 16;55(3):558-64.

45. Rueda A, Olmos D, Vicioso L, Quero C, Gallego E, Pajares-Hachero Bl, et al. Role of vascular endothelial growth factor $\mathrm{C}$ in classical Hodgkin lymphoma. Leuk Lymphoma. 2015 May 4;56(5):1286-94.

46. Riabov V, Gudima A, Wang N, Mickley A, Orekhov A, Kzhyshkowska J. Role of tumor associated macrophages in tumor angiogenesis and lymphangiogenesis. Front Physiol. 2014;5 MAR(March):1-13.

47. Marinaccio C, Nico B, Maiorano E, Specchia G, Ribatti D. Insights in Hodgkin Lymphoma angiogenesis. Leuk Res. 2014;38(8):857-61.

48. Vockerodt $M$, Tesch $H$, Kube D. Epstein-Barr virus latent membrane protein-1 activates CD25 expression in lymphoma cells involving the NFkappaB pathway. Genes Immun. 2001;2(8):433-41.

49. Kube D, Holtick U, Vockerodt M, Ahmadi T, Haier B, Behrmann I, et al. STAT3 is constitutively activated in Hodgkin cell lines. Blood. 2001;98(3):762-71. 
50. Zepeda-Moreno A, Taubert I, Hellwig I, Hoang V, Pietsch L, Lakshmanan VK, et al. Innovative method for quantification of cell-cell adhesion in 96-well plates. Cell Adh Migr. 2014 Oct 27;5(3):215-9.

51. Klingenberg M, Becker J, Eberth S, Kube D, Wilting J. The NADPH oxidase inhibitor imipramine-blue in the treatment of Burkitt lymphoma. Mol Cancer Ther. 2014 Apr;13(4):833-41. 


\section{Figure legends}

Figure 1: Constitutive active canonical WNT signaling of $\mathrm{cHL}$ cells affects chemotaxis.

(A) Representative stereo-microscopic overview and fluorescence-microscopic pictures (50-fold and 100-fold magnification) of GFP-labeled KM-H2 cells ex ovo, which migrate (arrow) along blood vessels. The $\mathrm{KM}-\mathrm{H} 2$ tumor on the CAM is framed in black and corresponding 20-fold magnifications of the stereo-microscopic and fluorescencemicroscopic pictures are shown on the right. (V-vessel; T-KM-H2 tumor on the CAM; Echick embryo)

(B) Migration of $\mathrm{L} 428$ and $\mathrm{KM}-\mathrm{H} 2$ cells for 6 hours after $24 \mathrm{~h}$ pre-treatment with 100ng/ml DKK1, DKK2 or DKK1 plus DKK2 was performed towards CCL19 in Boyden chamber assays. (mean $\pm \mathrm{SD}, \mathrm{n}=3$; 2-way ANOVA and Bonferroni's post-hoc test, significance level is shown compared to respective PBS control). $\left({ }^{* \star} \mathrm{P}<0.01\right.$ and ${ }^{* * *} \mathrm{P}<$ $0.001)$

(C) Migration of L428 and KM-H2 cells for 6 hours after 24 h pre-treatment with $5 \mu \mathrm{M}$ XAV939 or $0.05 \mu \mathrm{M}$ PF670462 was performed towards CCL19 in Boyden chamber assays. (mean $\pm \mathrm{SD}, \mathrm{XAV939}, \mathrm{n}=4$; PF670462, $\mathrm{n}=3$; 2-way ANOVA and Bonferroni's post-hoc test, significance level is shown compared to respective DMSO control). ( ${ }^{\star \star} \mathrm{P}<$ 0.01 and $\left.{ }^{* \star *} \mathrm{P}<0.001\right)$

(D) Western blot of cytosolic and nuclear fractions of L428 cells stimulated for 24 or 48 hours with conditioned medium (CM) or left untreated (ctrl). Note the increased nuclear $\beta$-catenin fraction after CM stimulation. As immunoblot controls, nuclear HDAC and 
cytosolic HSP90 amounts were determined to discriminate cytosolic and nuclear fractions. Relative $\beta$-catenin intensities compared to the respective cytosolic/nuclear controls are shown beneath (measured as area under the curve (AU) in \% of the respective cytosolic or nuclear control).

Figure 2: LEF-1 and $\beta$-catenin affect cell migration and invasion in cHL cells.

(A) Migration of L428 cells for 6 hours was performed towards CCL19 in Boyden chamber assays. L428 cells were transfected with LEF-1 siRNA 48 hours prior to the migration experiment. Note the decrease of $L 428$ cell migration after transient LEF-1 KD. (mean $\pm \mathrm{SD}, \mathrm{n}=4$; unpaired, 2-tailed t-test) $\left({ }^{* \star *} \mathrm{P}<0.001\right)$.

(B) Migration of L428 cells for 6 hours was performed towards CCL19 in Boyden chamber assays. L428 cells were transfected with $\beta$-catenin siRNA 48 hours prior to the migration experiment. Note the decrease of $L 428$ cell migration after transient transient $\beta$-catenin $K D$. (mean $\pm S D, n=3$; unpaired, 2-tailed t-test) $\left({ }^{* \star} P<0.01\right)$.

(C) Invasion of L428 and $\mathrm{KM}-\mathrm{H} 2$ cells was measured through type-1 collagen-coated membranes towards CCL19 in Boyden chamber assays after 16 hours. L428 and KM$\mathrm{H} 2$ cells were transfected with LEF-1 or $\beta$-catenin siRNA 48 hours prior to the invasion experiment. Note the decrease of invasion rates of LEF-1 and $\beta$-catenin KD cells. (mean $\pm \mathrm{SD}, \mathrm{n}=3,1$-way ANOVA and Bonferroni's post-hoc test, significance level is shown compared to respective scr si control) $\left({ }^{* * *} \mathrm{P}<0.001\right)$. 
(D) LEF-1 expression data obtained by Basso et al. ${ }^{30}$ were compared between cases of lymphoma/leukemia and subsets of untransformed physiological B-cells. Note the increased LEF-1 expression in analyzed lymphoma and leukemia cases. (mean \pm SD, each $n=5$ for B-lymphocytes, naive pre-GC B-lymphocytes, memory B-lymphocytes and centroblasts; Burkitt's Lymphoma, $n=31$; Hodgkin Lymphoma, $n=4$ (cell lines); DLBCL, $\mathrm{n}=41 ; \mathrm{CLL}, \mathrm{n}=34$; 1-way ANOVA and Bonferroni's post-hoc test).

(E) LEF-1 expression data obtained by Brune et al. ${ }^{29}$ were compared between $\mathrm{cHL}$ patient samples and subsets of untransformed physiological B-cells. Note the significantly higher $L E F-1$ expression in $\mathrm{cHL}$ patient samples. (mean $\pm \mathrm{SD}$, each $\mathrm{n}=5$ for naive pre-GC B-lymphocytes, memory B-lymphocytes, small cleaved follicle center B cells, centroblasts and plasma cells; Hodgkin Lymphoma, $n=12$ (patient material); 1-way ANOVA and Bonferroni's post-hoc test). ( ${ }^{* *} P<0.01$ and $\left.{ }^{* * *} \mathrm{P}<0.001\right)$.

(F) Immunohistochemical staining of LEF-1-positive (left) and negative (right) HRS cells of mixed-cellularity type patients. HRS cells show nuclear LEF-1 staining only in the left case (inlet), whereas in some bystander cells also the nuclear LEF-1 staining can be observed.

Figure 3: LEF-1 and $\beta$-catenin influence cell path characteristics of $\mathrm{cHL}$ cells in a 3D matrix.

(A) $\mathrm{KM}-\mathrm{H} 2$ scr si control, LEF-1 and $\beta$-catenin KD cells have been embedded in type-1 collagen in $\mu$-Slide chemotaxis ${ }^{3 \mathrm{D}}$ chambers (Ibidi, Martinsried, Germany) and their cell 
tracks towards CCL19 have been observed using time-lapse microscopy. Representative trajectory dot plots show the sector distribution of corresponding cells. Single cell tracks covering more than $75 \mu \mathrm{m}$ Euclidean distance are colored in red. For group directionality the center of masses is shown as yellow dot. The triangle CCL19 indicates the chemotactic gradient. Beneath the dot plot one representative cell movement is shown over time. Note the impaired directionality in LEF-1 and $\beta$-catenin KD cells.

(B) Velocities of LEF-1 and $\beta$-catenin $\mathrm{KD}$ KM-H2 cells are significantly reduced compared to control scr si cells (mean $\pm \mathrm{SD} ; \mathrm{n}=3$ of each 50 trajectories; Kruskal-Wallis test, $\left.{ }^{* * *} \mathrm{P}<0.001\right)$.

(C) Euclidean distances of LEF-1 and $\beta$-catenin KD KM-H2 cells are significantly reduced compared to control scr si cells (mean $\pm S D ; n=3$ of each 50 trajectories; Kruskal-Wallis test, $\left.{ }^{* * *} \mathrm{P}<0.001\right)$.

(D) Accumulated distances of LEF-1 and $\beta$-catenin KD KM-H2 cells are significantly reduced compared to control scr si cells (mean $\pm S D ; n=3$ of each 50 trajectories; Kruskal-Wallis test, $\left.{ }^{* \star *} \mathrm{P}<0.001\right)$.

(E) The fifteen most different movement classes out of $450 \mathrm{KM}-\mathrm{H} 2$ cell tracks are shown and the corresponding distribution within each group of scr si, LEF-1si and $\beta$-catenin si KM-H2 cells. Classes $8-11$ are characterized by low directionality movements. These low directionality movement classes are dominant for LEF-1 and $\beta$-catenin KD KM-H2 cells. 
Figure 4: LEF-1 modifies the influence of $\mathrm{cHL}$ cells on endothelial cell migration.

(A) Migration of HUVECs towards $\mathrm{CM}$ of $\mathrm{KM}-\mathrm{H} 2$, ns control (non-silenced) and LEFsh cells in modified Boyden chamber after 4 hours. As positive control HUVEC migration towards EBM2 medium supplemented with EGM-2 MV SingleQuot Kit Supplements \& Growth Factors and as negative control RPMI medium have been used. (mean \pm SD, $n=3$, Kruskal-Wallis test with Bonferroni's post-hoc test). ( ${ }^{* \star} P<0.01$ and ${ }^{* * *} P<0.001$ ).

(B, C) Scratch assay of HUVEC cells towards $\mathrm{CM}$ of $\mathrm{KM}-\mathrm{H} 2$, ns control (non-silenced) and LEF-1sh cells. As positive control HUVEC migration in EBM2 medium supplemented with EGM-2 MV SingleQuot Kit Supplements \& Growth Factors and as negative control RPMI medium was analyzed. Note the decrease in HUVEC migration towards $\mathrm{CM}$ of KM-H2 after LEF-1 knockdown (KD). (mean $\pm \mathrm{SD}, \mathrm{n}=3$; Kruskal-Wallis test with Bonferroni's post-hoc test).

Figure 5: LEF-1 and $\beta$-catenin modify the influence of $\mathrm{cHL}$ cells on endothelial cell sprouting, tube formation and adhesion of cHL cells to ECs or type-1 collagen.

(A) Representative pictures of sprouting HUVEC spheroids grown in conditioned medium (CM) of KM-H2 ns control (non-silenced) or LEF-1 knockdown (KD) cells are shown (100-fold magnification). As positive control EBM2 medium has been used (described in Figure 4) to induce strong sprouting by the HUVEC cells. 
(B) Quantitative analysis of the frequency of sprouting events. Note that the only difference between control and LEF-1 KD CM is the sprouting frequency. Spheroids grown in RPMI medium do not sprout. (mean $\pm S D, n=3$ of each $12-20$ spheroids).

(C) Quantification of the cumulative sprout lengths. (mean $\pm S D, n=3$ of each $12-20$ spheroids)

(D) Quantification of the number of sprouting tips (mean $\pm S D, n=3$ of each $12-20$ spheroids).

(E) Representative pictures of HUVEC tubes formed in KM-H2 scrambled control, LEF-1 or $\beta$-catenin KD CM (100-fold magnification). The tube formation capacity is reduced by LEF-1 and $\beta$-catenin KD in KM-H2 cells. As positive control EBM2 medium has been used (described in Figure 4). Please note that HUVEC cells do not form any tubes in RPMI 1640 medium.

(F) For tube formation quantification cumulative tube lengths have been measured. Cumulative tube lengths are significantly reduced in HUVEC cells treated with CM of KM-H2 LEF-1 or $\beta$-catenin KD cells. (mean $\pm S D, n=3$ of each 4 wells; 1 -way ANOVA and Bonferroni's post-hoc test) $\left({ }^{* *} \mathrm{P}<0.01\right)$.

(G) Adhesion of scr si control, LEF-1si and $\beta$-catenin si KM-H2 cells on either HUVEC (white) or collagen I (grey). Adhesion of LEF-1si cells is decreased compared to scr si cells. (mean $\pm \mathrm{SD}, \mathrm{n}=4,2$-way ANOVA and Bonferroni's post-hoc test) $\left({ }^{\star} \mathrm{P}<0.05\right)$.

Figure 6: Impaired canonical Wnt signaling by XAV939 treatment affects lymphoma outcome in the chick chorio-allantoic membrane (CAM) assay. 
(A) Tumor area is reduced after XAV939 pretreatment of $\mathrm{CHL}$ cells. $\mathrm{L} 428$ and $\mathrm{KM}-\mathrm{H} 2$ cells were pre-treated for 24 hours with XAV939, inoculated on the CAM and harvested after four days of tumor growth. To evaluate the lymphoma outcome, tumor areas of L428 and KM-H2 tumors were measured (mean \pm SD, L428 DMSO, $\mathrm{n}=19$; L428 XAV939, $\mathrm{n}=21 ; \mathrm{KM}-\mathrm{H} 2$ DMSO, $\mathrm{n}=11 ; \mathrm{KM}-\mathrm{H} 2$ XAV939, $\mathrm{n}=10 ; 2$-way ANOVA and Bonferroni's post-hoc test). ${ }^{* \star} \mathrm{P}<0.01$ and $\left.{ }^{* \star *} \mathrm{P}<0.001\right)$.

(B) Tumor hemorrhages are reduced after XAV939 pretreatment of $\mathrm{cHL}$ cells. Measurement of corresponding hemorrhage scores of $\mathrm{L} 428$ and $\mathrm{KM}-\mathrm{H} 2$ tumors. (mean \pm SD, L428 DMSO, $n=19$; L428 XAV939, $n=21 ; K M-H 2$ DMSO, $n=11 ; K M-H 2$ XAV939, $\mathrm{n}=10$; Mann-Whitney test). ( ${ }^{*} \mathrm{P}<0.05$ and ${ }^{* * *} \mathrm{P}<0.001$ ).

(C) Representative stereo-microscopic photos (7.8x magnification) of L428 and KM-H2 lymphoma. Note the decreased size and reduced bleedings in XAV939 treated tumors.

(D) H\&E staining of CAM KM-H2 lymphomas that have been pre-treated with DMSO or XAV939. Black arrows indicate strong bleeding and hemorrhage areas around vessels in DMSO treated tumors. Yellow arrows point at intact small vessels in tumors of XAV939 pre-treated KM-H2 cells.

(E) Volume rendered Micro-CT data sets of exemplary lymphomas of KM-H2 cells pretreated with DMSO (left) or XAV939 (right). The above shown picture represents the whole lymphoma. Beneath are corresponding virtually cut sections. Black arrows indicate vessel structures inside the tumors. Note the neovascularization in lymphomas from DMSO pre-treated KM-H2 cells from one of the main CAM vessels; a reduced 
vascular network is observed in XAV939-treated tumors, despite their access to CAM vessels $($ bar $=3 \mathrm{~mm})$.

Figure 7: VEGF-A secretion of cHL cells is reduced by LEF-1/ $\beta$-catenin and high VEGFA gene expression is associated with a worse clinical outcome in cHL patients.

(A) VEGF-A levels of scr si control, LEF-1si and $\beta$-catenin si $\mathrm{L} 428$ and $\mathrm{KM}-\mathrm{H} 2$ cell supernatants from three independent nucleofections were measured using ELISA and normalized to the $10^{5}$ cells per ml. Note the decreased VEGF-A levels after LEF-1 and $\beta$-catenin KD. (mean $\pm S D, n=3)$.

(B) VEGFA expression data obtained by Steidl et al. ${ }^{34}$ was correlated with the overall survival of $\mathrm{cHL}$ patients. High VEGFA gene expression is associated with a significant shorter overall survival for $\mathrm{cHL}$ patients. (mean $\pm \mathrm{SD}$, low, $\mathrm{n}=56$; high, $\mathrm{n}=68$; Log-rank Mantel-Cox test, ${ }^{* *} \mathrm{P}<0.01$ ). 

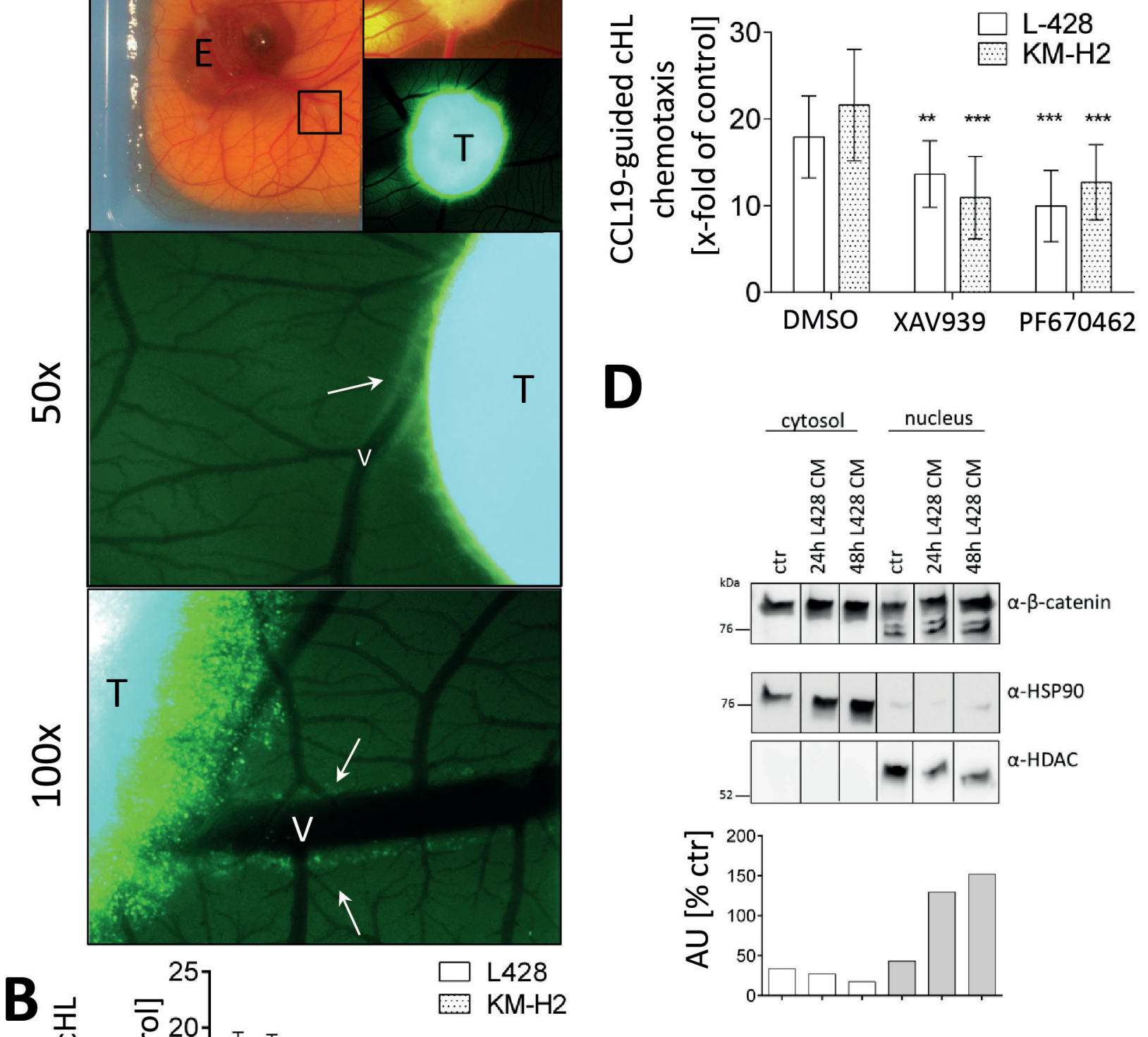

D
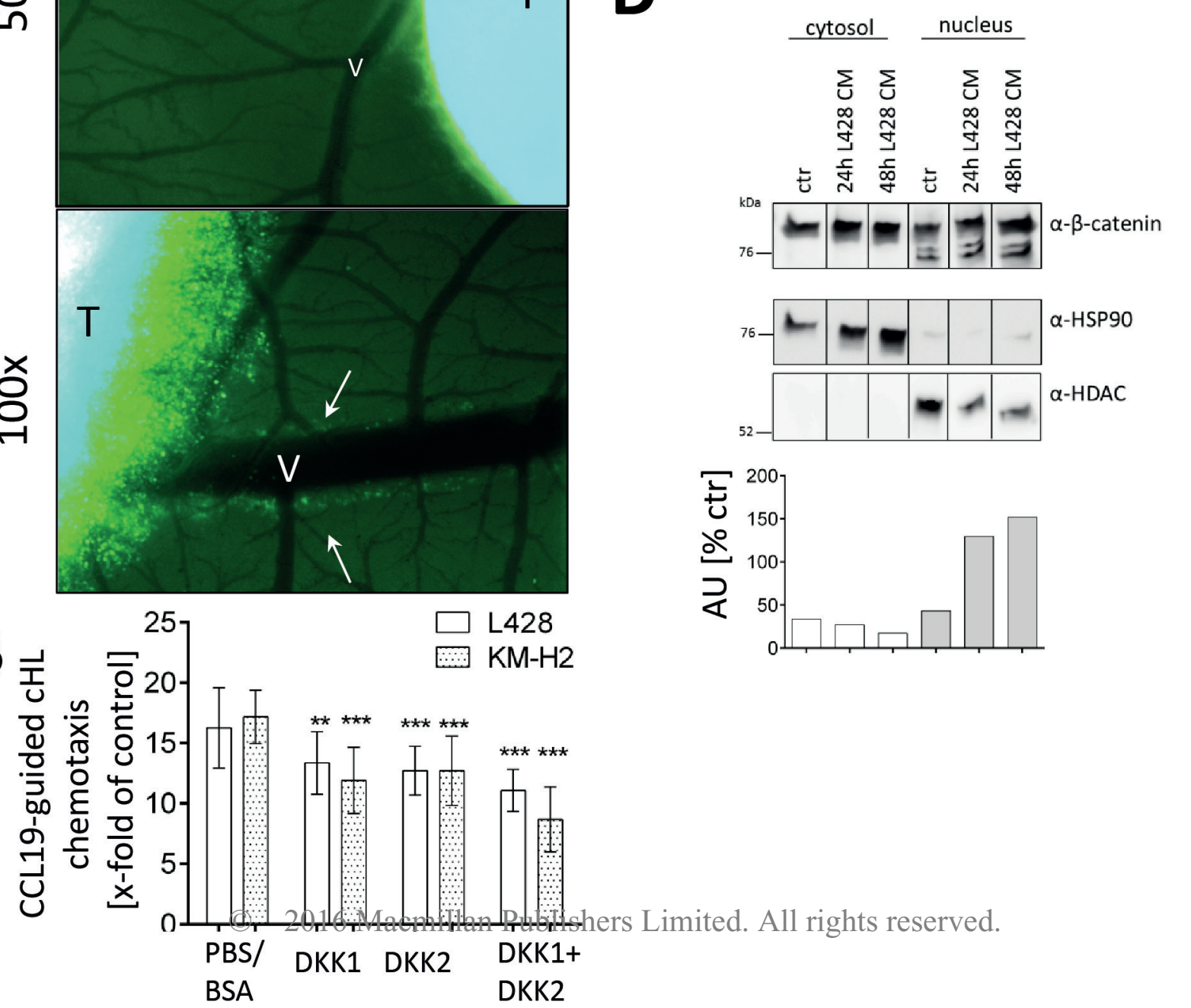

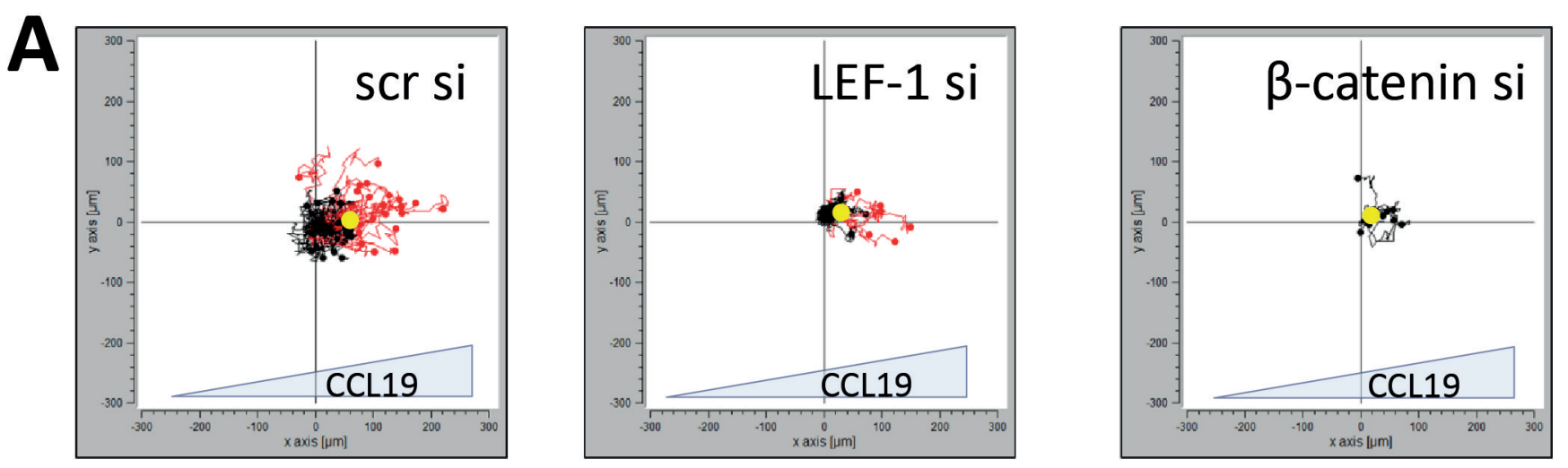

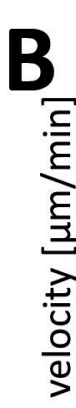
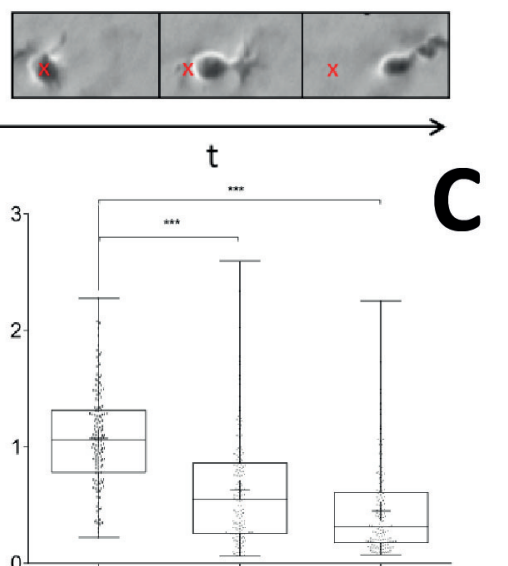

scr si LEF-1 si $\beta$-catenin si
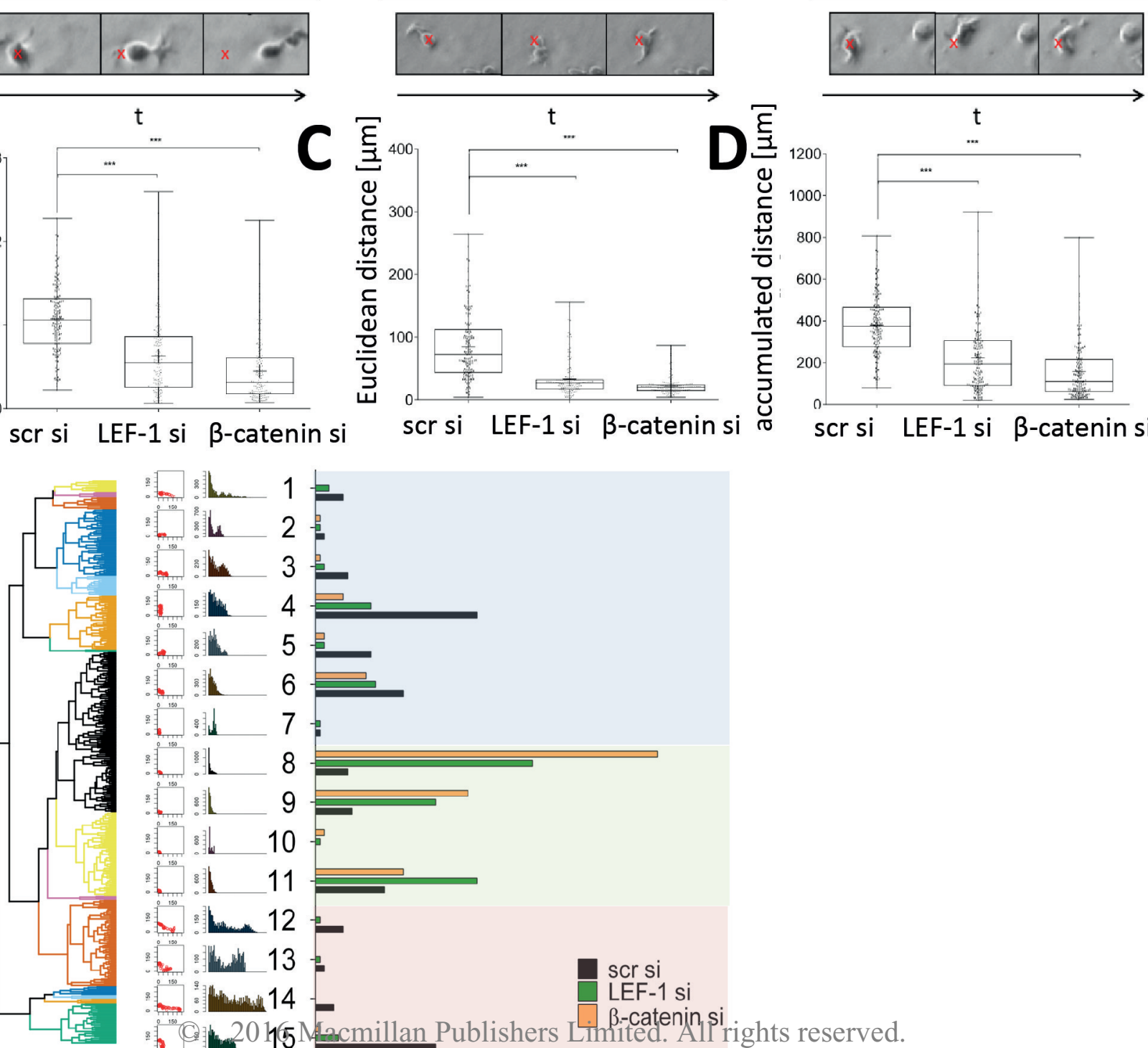

C $2015 \mathrm{M}$ acmillan Publishers Linited. All rights reserved.

relative distribution within a group [\%] 


\section{A}
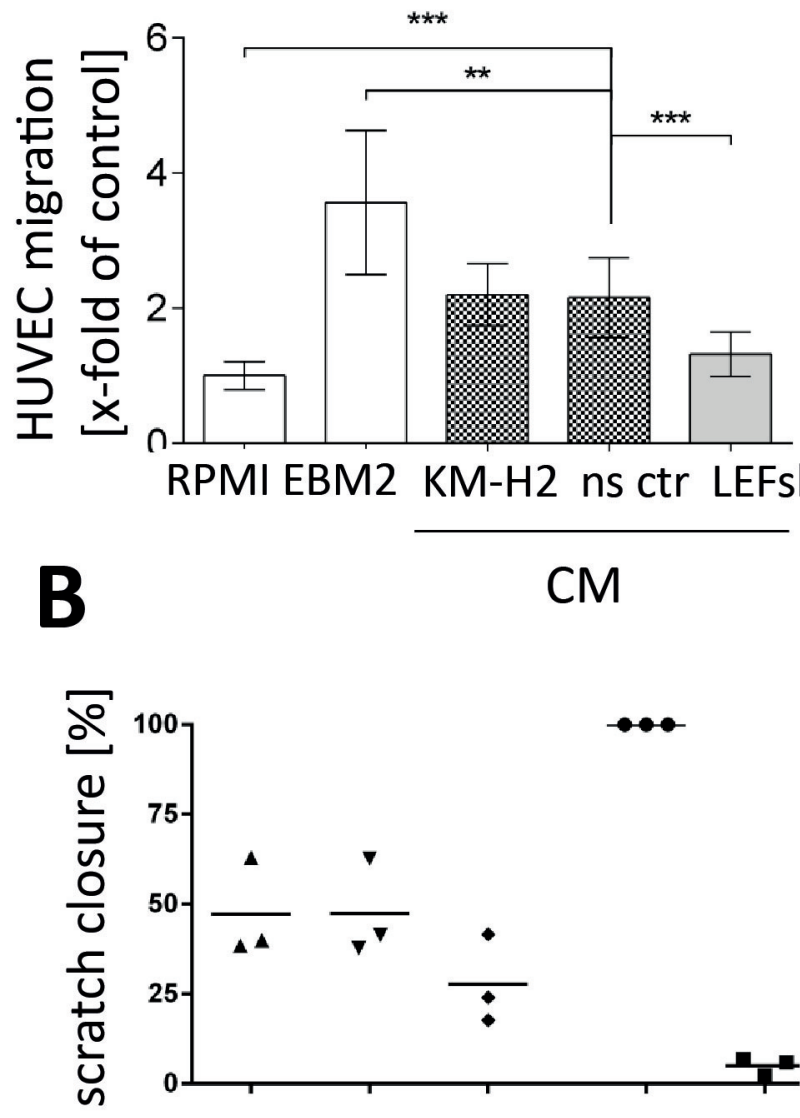

$\mathrm{Oh}$
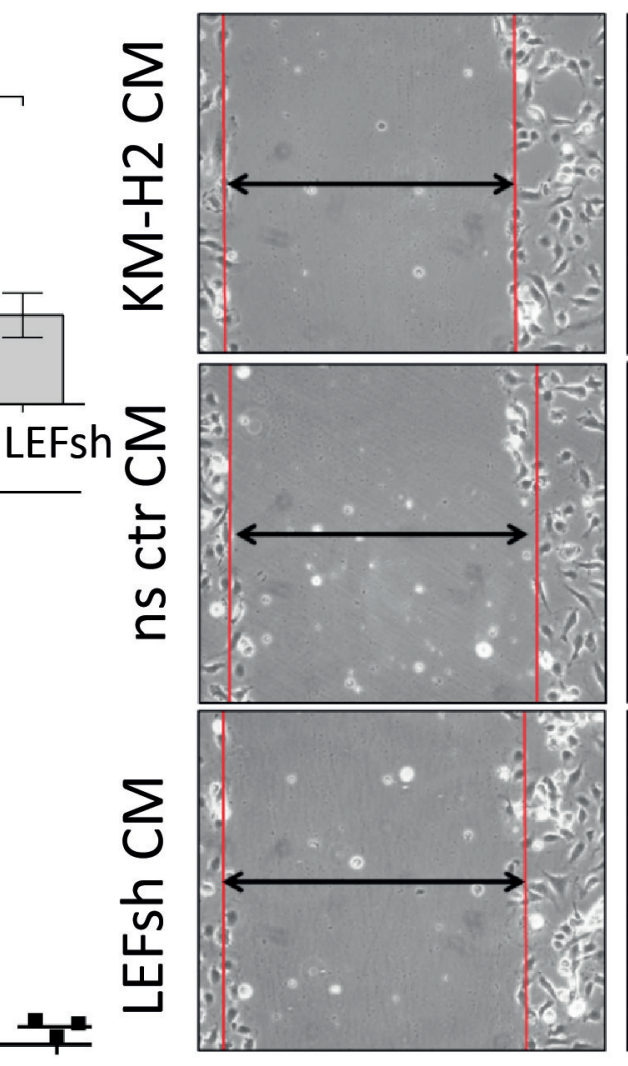

KM-H2 ns ctr LEFsh EBM2 RPMI

CM

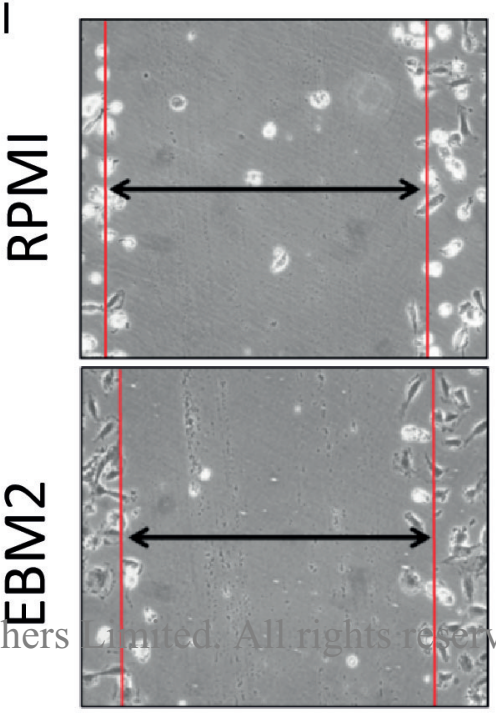

$16 \mathrm{~h}$
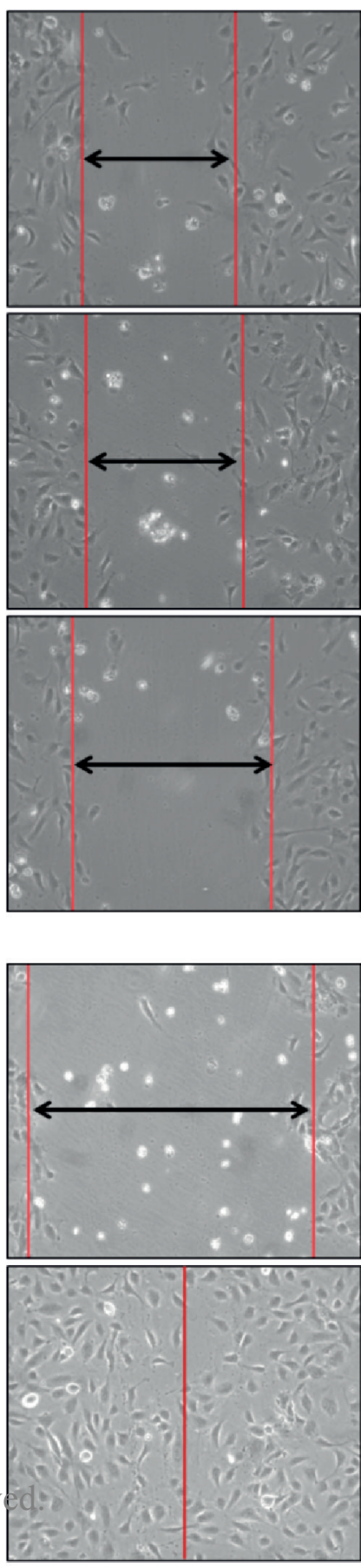

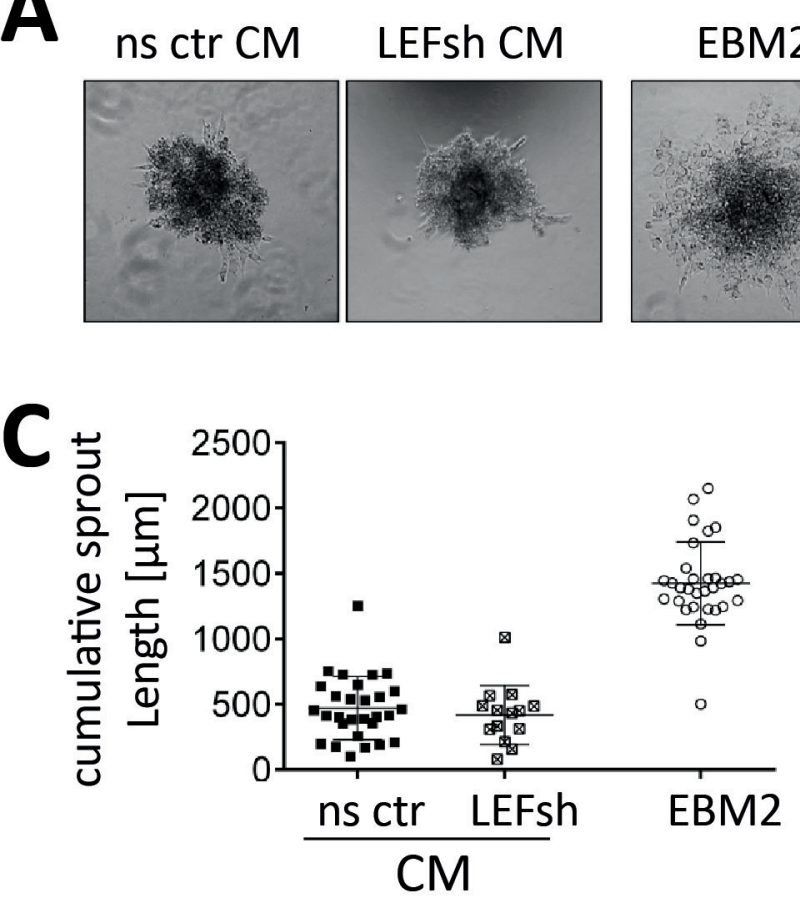
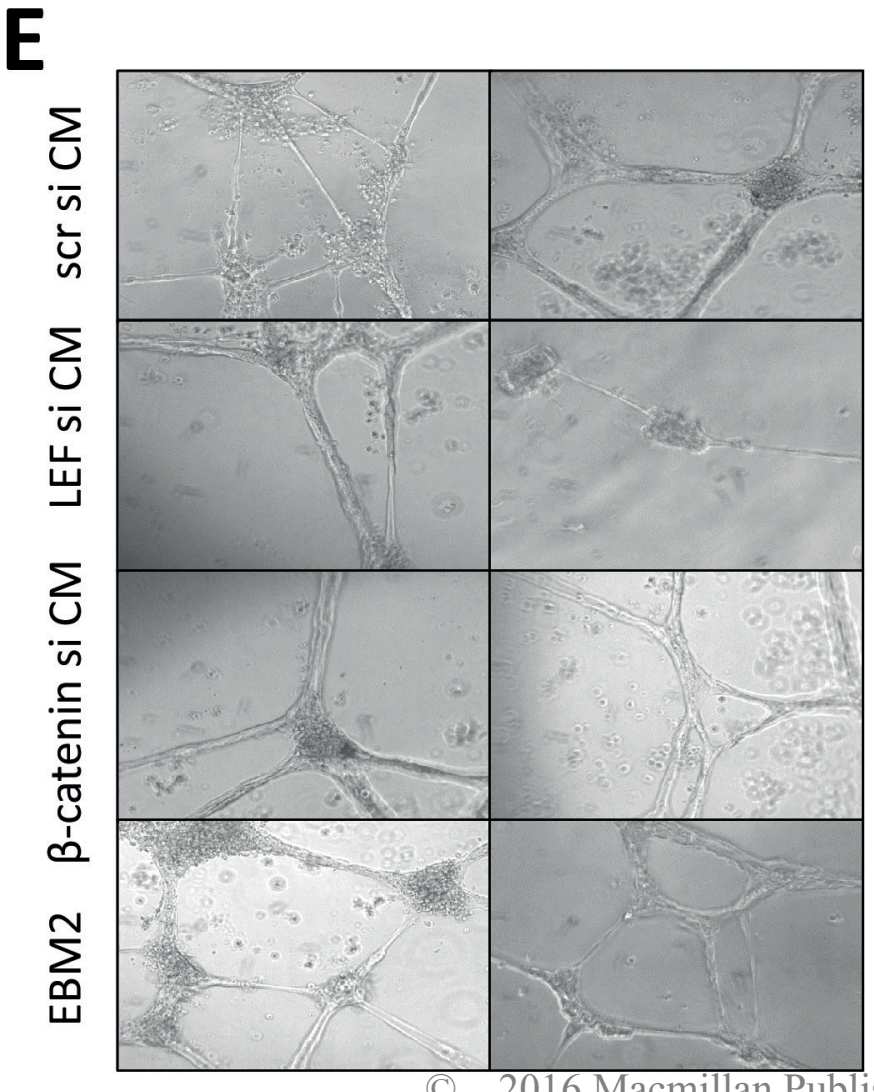

F
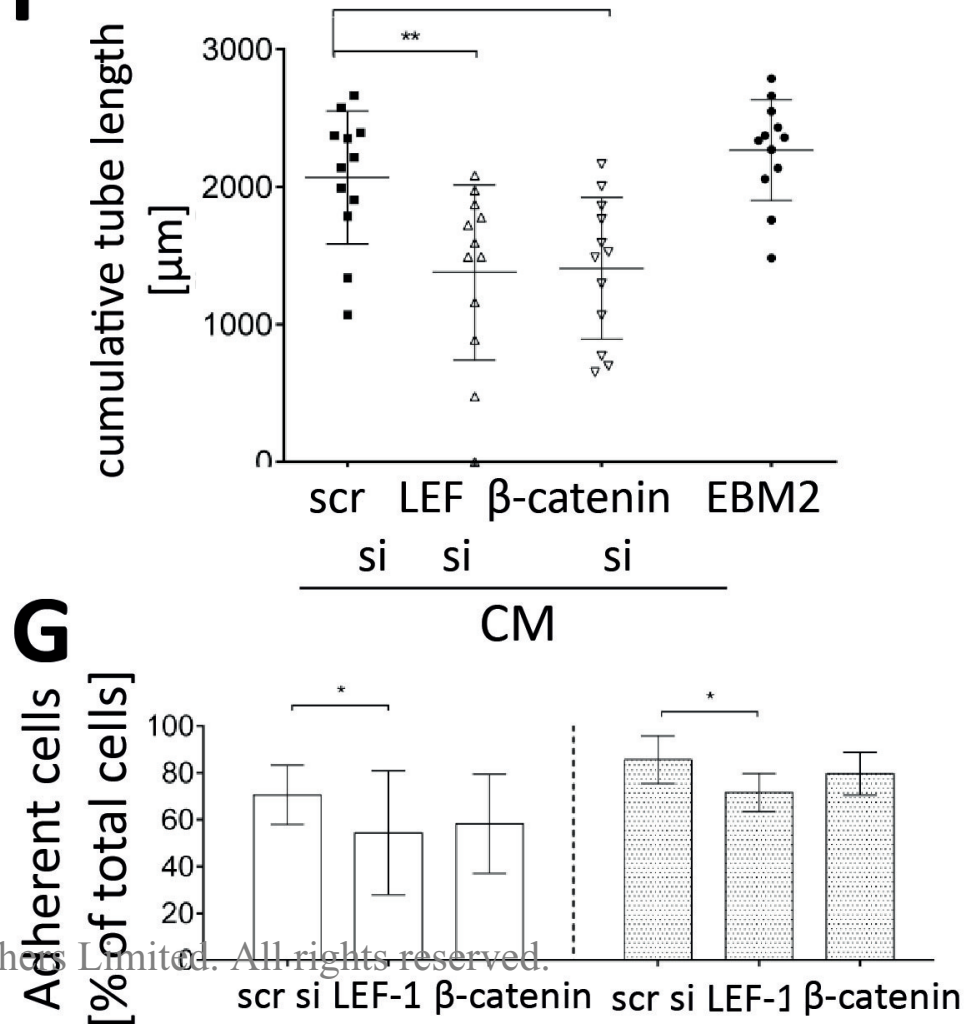
si 
A

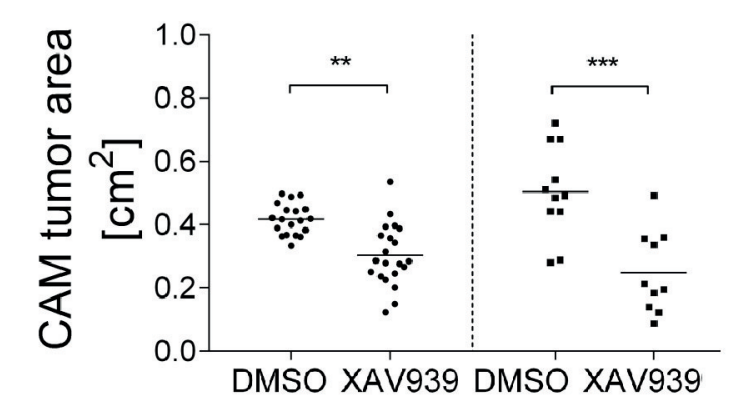

C
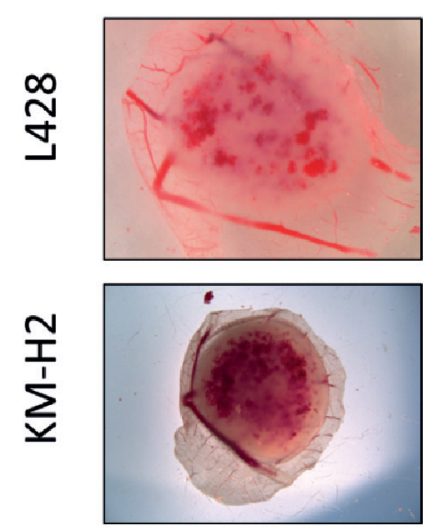

D
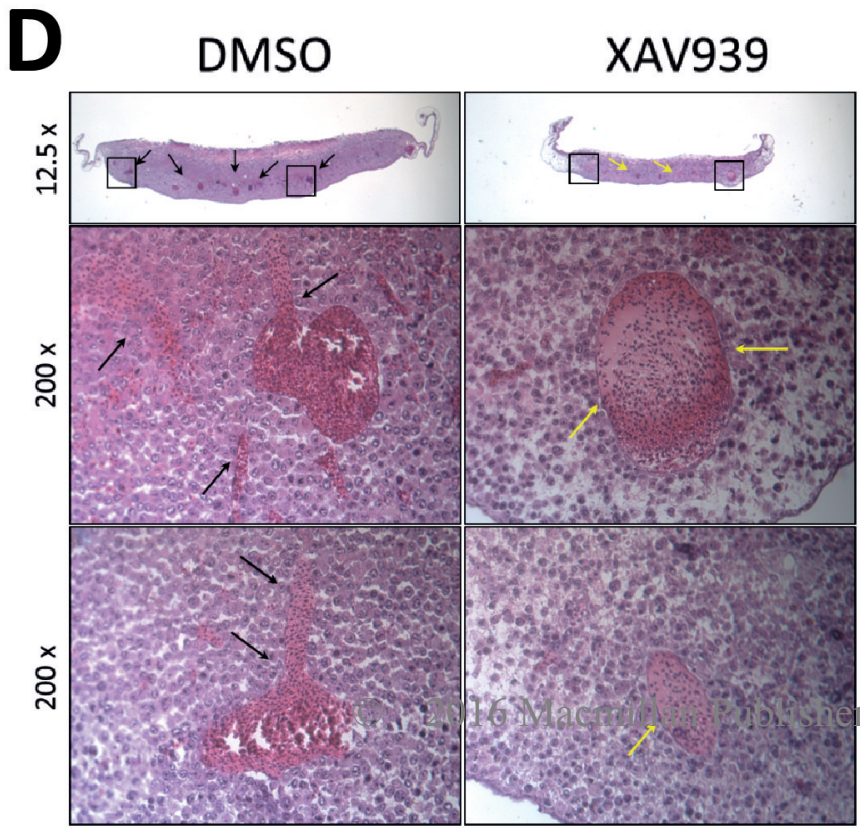

XAV939
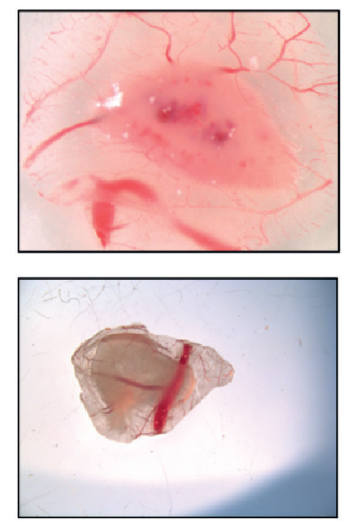

XAV939
$\mathrm{KM}-\mathrm{H} 2$
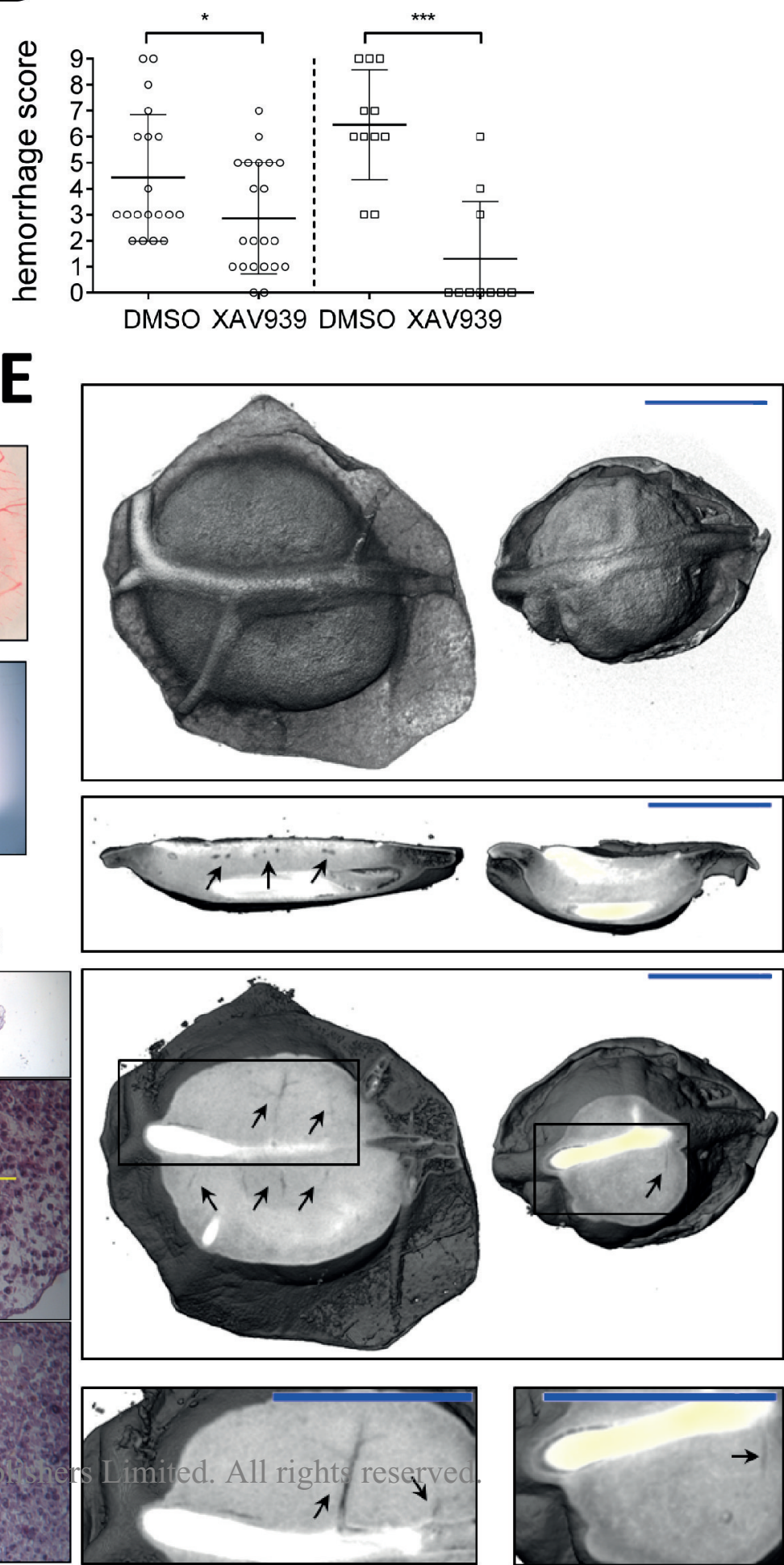
- L428

B

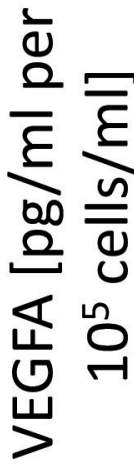

- $\mathrm{KM}-\mathrm{H}_{2}$
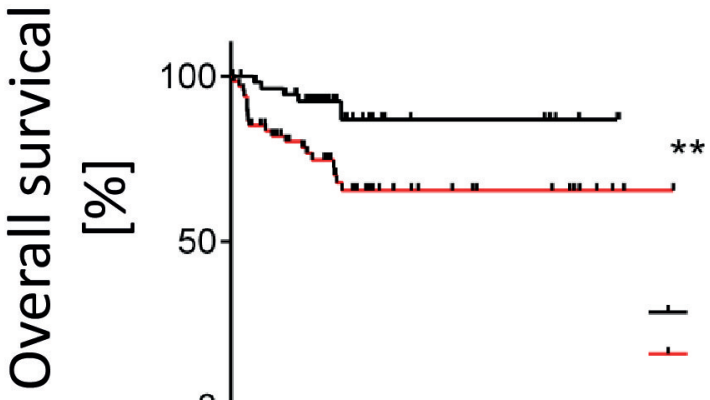

+ low

+ high

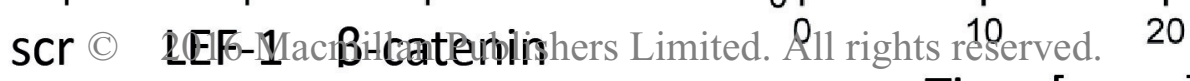

30

si

si

si

Time [years] 